\title{
Treatment with nano-silica and bacteria to restore the reduced bond strength between concrete and repair mortar caused by aggressive removal techniques
}

\author{
Mohammad Ali Yazdi ${ }^{1}$, Elke Gruyaert ${ }^{2}$, Kim Van Tittelboom $^{1}$, Nico Boon ${ }^{3}$, Nele De Belie ${ }^{1}$ \\ ${ }^{1}$ Ghent University, Magnel Laboratory for Concrete Research, Department of Structural \\ Engineering and Building Materials, Tech Lane Ghent Science Park, Campus A, \\ Technologiepark Zwijnaarde 60, 9052 Gent, Belgium
}

${ }^{2}$ KU Leuven, Department of Civil Engineering, Ghent Technology Campus, Gebroeders De Smetstraat 1, 9000 Gent, Belgium

${ }^{3}$ Ghent University, Center for Microbial Ecology and Technology (CMET), Coupure Links 653, B-9000, Gent, Belgium

\begin{abstract}
:
Removal of degraded concrete during repair activities might have a detrimental impact on the bond strength between the concrete and the repair mortar. This research aims to improve the bonding strength in case aggressive removal techniques were used, by the singular and combined application of bacterially induced $\mathrm{CaCO}_{3}$ and colloidal nano-silica (CNS) treatments. Water jetting (WJ) and jackhammering $(\mathrm{JH})$ were compared and the treatments were performed on the substrates prepared with the technique causing the lowest bonding. Pull-off test results on crushed stone concrete (CC) substrates showed that $\mathrm{JH}$ substrates possessed the lowest bond strength compared to $\mathrm{WJ}$ and unprepared substrates. To assure that reported results are reproducible, pull-off tests were also performed on another type of concrete, gravel concrete (GC). The results showed that in both cases JH-substrates achieved a lower bond strength than unprepared- and WJ-substrates. The reduced bond strength by JH was restored by the CNS treatment irrespective of the concrete composition. Regarding the biodeposition treatment, the spraying technique showed to be superior to the pouring technique. Microstructural analysis confirmed the survival of the bacteria and carbonate precipitation. Porosity of the prepared substrate surfaces was studied by capillary absorption, water absorption (including the gravity effect) and vacuum absorption tests. The reduction in the initial water uptake of CNS-treated samples was evidenced by the precipitation of the silica gel at the superficial layer of the substrate. The efficacy of Energy Dispersive X-Ray Analysis (EDX) to recognize the interlayer of layered composites with a monolithic structure was observed.
\end{abstract}

Keywords: concrete removal techniques; bond strength; colloidal nano-silica; bacterial treatment; microscopy analysis; porosity. 


\section{Introduction}

Concrete removal techniques are widely used to remove contaminated concrete. However, many bonding failures in repair systems are attributed to too aggressive removal of the contaminated concrete $[1,2]$. Some "aggressive" techniques, e.g. jackhammering $(\mathrm{JH})$ may weaken the remaining substrate by creating microcracks, fractured surfaces (bruising), etc. and so impair the bond strength between the concrete substrate and the repair material $[1,3]$. No solution has so far been proposed on how to recover the lost bond strength. Some researchers have proposed the usage of techniques such as high-pressure water jetting [4] or sandblasting (SB) after the use of JH [4-7]. However, SB is banned in some countries such as UK due to the environmental and human health issues it causes [8]. And the former is not economically-friendly and demands too much effort [6]. Only in [5] JH substrates were compared quantitatively with samples that were JH followed by SB. As the results showed, the average bond strength at 6 months increased by $12 \%$ when JH samples were exposed to SB afterwards. The influence of removal techniques on the substrate, and as a result, the bond strength depends not only on the removal techniques themselves, but it is also dependent on factors such as the removal energy and the substrate properties (e.g. aggregate size, mechanical strength, porosity, etc.) [1]. Researchers in [1] reported the influence of aggregate size and shape on the microcrack density and roughness of samples exposed to concrete removal techniques such as $\mathrm{WJ}$ and $\mathrm{JH}$. According to their results, concrete samples with the largest aggregate size obtained the highest microcrack density and roughness. Two removal techniques, water jetting (WJ) and jackhammering $(\mathrm{JH})$, that belong to the same classification (able to remove a significant layer of deteriorated concrete) [9] are compared in the current study and the one resulting in the lowest bond underwent nano-material and/or bacterial treatments for the bond improvement.

Different surface treatment techniques have been used to protect the surface of existing concretes and so improve the performance and extend their service life [10]. Some of these treatments act like porefillers (silicate-based solutions), some create a water-repellent surface without blocking the pores (hydrophobic impregnation, e.g. silane, siloxane, etc.) and the last group forms a physical coating-barrier at the surface of the concrete [11]. A large number of studies have been performed on the application of these treatments and their effect on the performance of concrete [11-14] and it has widely been reported that the silicate-based solutions have a more moderate impact on the permeability of the concrete compared to the other techniques [11, 15]. Baltazar et al. [11] and Franzoni et al. [12] used silicatebased impregnation products for the surface protection of concrete. In both studies, an improvement in the permeability of mixtures was observed. However, results in the former study [11] showed the uneffective role of the surface treatment on the impact resistance of samples. The current study is aimed to introduce a method of treatment not only to improve the performance of the concrete, but also to improve the adhesion between the substrate and the repair material.

Nano-silica (NS) in the form of a solution or a solid has been widely used in construction materials [10, 16-19]. Hou et al. studied the effect of colloidal NS (CNS) on the cement hydration and reported an increase in high-stiffness C-S-H [20]. In another study, the permeability of hardened cement pastes reduced when their surface was treated with CNS [17]. Researchers in [21] could change the pore structure of hardened cement pastes with the surface treatment by CNS and therefore reduced the water absorption ratio of samples. Theoretically, it is expected that the amorphous silica produces more C-S$\mathrm{H}$ gel through the consumption of cement reaction products such as calcium hydroxide $[15,17,20]$. However, not enough attention has been paid to the reaction between the colloidal nano-silica (CNS) and hardened binder, leaving an important question open: "whether or not CNS reacts when added to a hardened concrete substrate before applying a repair mortar". In order to answer this question, in this study, the surface tensile strength of pre-treated JH substrates with CNS was studied.

One the other hand, biodeposition treatment has proved to be a novel, environmentally friendly, and effective method for healing or consolidating concrete materials and stones by inducing a dense layer of precipitated $\mathrm{CaCO}_{3}$ crystals. This layer can be induced by ureolytic bacteria, e.g. Bacillus sphaericus, 
which possess the urease enzyme, enabling them to hydrolyse urea into ammonia and carbonate ions. Some researchers used this method for remediation of cracks in concrete [22-24] or to improve the durability of cement-based materials [25, 26]. De Muynck et al. [26] used bacterial carbonate precipitation (Bacillus sphaericus) for the surface treatment of mortar samples and achieved a lower capillary water absorption and gas permeability. It has also been used for repair of stones such as limestone monuments [27,28]. Effect of $\mathrm{CaCO}_{3}$ induced by bacterial treatment (Sporoscarcina pasteurii bacteria) on the mechanical strength of concrete samples containing fly ash has been investigated in [29]. An improvement by $22 \%$ in the compressive strength was reported as a result of the use of $10^{5}$ cells $/ \mathrm{ml}$ cell concentration of bacteria in the concrete mix. Snoeck et al. [30] formed different roughness levels on a mortar substrate by introducing the bacterially induced $\mathrm{CaCO}_{3}$ before application of the repair mortar and evaluated the bond quality based on slant shear tests. Their results showed an improvement in the bond strength between the substrate and repair mortar induced by the increased roughness.

The effect of concrete removal techniques on the substrate and so the bond strength with the repair mortar is not negligible. Therefore, the main objective of this paper is to first investigate the influence of the removal techniques on the substrate properties and hence the bond with the overlay. The impact of the surface preparation on the durability of the bonding was also assessed by the performance of pulloff tests at different ages of 28 days and 12 months. Water uptake, surface tensile strength and roughness of the substrate were investigated to assess the removal technique effects on the concrete substrate. The removal technique with the highest detrimental impact on the substrate and so the bond was selected for further investigations. Moreover, it is crucial to restore the lost bond caused by the removal technique. Hence, the second goal of the study is to introduce a novel solution to restore the lost bond induced by the aggressive removal technique. To this end, $\mathrm{CNS}$ and bacterially induced $\mathrm{CaCO}_{3}$ were employed in singular and combined strategies. Pull-off tests were performed at the end to quantify the restored bond strength and the surface tensile strength, and also capillary absorption were executed on concrete substrates to assess the porosity of surface-treated samples.

\section{Materials and methods}

\subsection{Materials}

In this study, CEM I $52.5 \mathrm{~N}$, gravel $2 / 8$ and $8 / 16$ or crushed limestone $2 / 6.3$ and $6.3 / 20$ together with sand were used as solids to prepare concrete slabs. Superplasticizer Glenium 27 from BASF and Viscocrete 1020x from SIKA were respectively added to crushed limestone concrete and gravel concrete mixtures until the slump reached around $120 \pm 20 \mathrm{~mm}$. For bond strength measurements, the surface of substrates was overlaid with a layer (thickness $15 \pm 5 \mathrm{~mm}$ ) of BASF MasterEmaco S 5400 repair mortar. For biodeposition treatment, B. sphaericus LMG 22557 bacteria (BCCM, Gent) with a concentration of $10^{9}$ cells $/ \mathrm{ml}$ was used in this study together with urea $(0.5 \mathrm{~mol} / \mathrm{l})$ as nutrient and calcium chloride $(0.5$ $\mathrm{mol} / \mathrm{l}$ ) as calcium source. The bacterial culture was prepared following the instructions given in [30]. Moreover, colloidal nano-silica (CNS) with a nominal particle size of 12 nanometer and density of 1.3 $\mathrm{g} / \mathrm{cm}^{3}$ was supplied by the GRACE company and used to treat samples. The alkaline aqueous solution contains $40 \%$ amorphous silicon dioxide $\left(\mathrm{SiO}_{2}\right)$. CNS with small nominal size was chosen to facilitate the penetration into the substrate.

\subsection{Slab preparation}

Two series of concrete slabs were manufactured in this study. The first series was prepared with crushed limestone concrete (CC) having dimensions of $1000 \mathrm{~mm} \times 1000 \mathrm{~mm} \times 200 \mathrm{~mm}$ and $2000 \mathrm{~mm} \times 1000$ $\mathrm{mm} \times 200 \mathrm{~mm}$. These slabs were respectively exposed to jackhammering $(\mathrm{JH})$ and water jetting $(\mathrm{WJ})$ removal techniques on the as-cast surface at the age of 3 months or older. Half of the larger slab was not exposed and remained as control (unprepared). Afterwards, each slab was sawn into samples of $330 \mathrm{~mm}$ x $330 \mathrm{~mm}$ x $200 \mathrm{~mm}$. In this study, experiments were performed on the as-cast surface of the unprepared samples. The second series of slabs were prepared with gravel concrete (GC) having dimensions of 300 
$\mathrm{mm} \times 300 \mathrm{~mm} \times 100 \mathrm{~mm}$. GC slabs underwent $\mathrm{JH}$ on the as-cast surface at the age of 12 months or older. The former (CC) was used to study the effect of removal techniques and also of biodeposition and colloidal nano-silica (CNS) treatments. The second series was prepared to assure that the reported results are reproducible. The mix composition of each is given in Table 1. It should be mentioned that for biodeposition, nano-silica and their combined application, samples with dimensions of $110 \mathrm{~mm} x$ $330 \mathrm{~mm}$ x $200 \mathrm{~mm}$ and $110 \mathrm{~mm} \times 300 \mathrm{~mm}$ x $100 \mathrm{~mm}$ were sawn from the CC and GC slabs respectively for bond strength (BS) and surface tensile strength (STS) measurements. And for porosity measurements cores of $100 \mathrm{~mm}$ diameter and $100 \mathrm{~mm}$ height were drilled from CC substrates. More detailed information is given in Table 2 and each related section.

Table 1. The concrete substrate mix design and characteristics.

\begin{tabular}{ccc}
\hline Materials & Gravel Concrete $(\mathrm{GC})$ & $\begin{array}{c}\text { Crushed Limestone Concrete } \\
(\mathrm{CC})\end{array}$ \\
\hline CEM I $52.5 \mathrm{~N}\left(\mathrm{~kg} / \mathrm{m}^{3}\right)$ & 340 & 340 \\
Water $\left(\mathrm{kg} / \mathrm{m}^{3}\right)$ & 153 & 153 \\
Sand $\left(\mathrm{kg} / \mathrm{m}^{3}\right)$ & 604 & 604 \\
Gravel $2 / 8\left(\mathrm{~kg} / \mathrm{m}^{3}\right)$ & 336 & \\
Gravel $8 / 16\left(\mathrm{~kg} / \mathrm{m}^{3}\right)$ & 967 & 336 \\
Crushed limestone $2 / 6.3\left(\mathrm{~kg} / \mathrm{m}^{3}\right)$ & & 967 \\
Crushed limestone 6.3/20 $\left(\mathrm{kg} / \mathrm{m}^{3}\right)$ & & $*$ \\
Superplasticizer Glenium 27 & $*$ & 0.45 \\
Superplasticizer Viscocrete 1020x & 0.45 & \\
Water/Cement ratio $(\mathrm{w} / \mathrm{c})$ & $39.60 \pm 6.20(28 \mathrm{~d})$ & $68.40 \pm 2.47(90 \mathrm{~d})$ \\
Compressive strength mean \pm & & \\
standard deviation $\left(\mathrm{N} / \mathrm{mm}^{2}\right)$ & &
\end{tabular}

"The amount of superplasticizer was adjusted to obtain $120 \pm 20 \mathrm{~mm}$ slump. Range of aggregate sizes are given as 2/8 $\mathrm{mm}$ and $8 / 16 \mathrm{~mm}$ for gravel, and 2/6.3 $\mathrm{mm}$ and $6.3 / 20 \mathrm{~mm}$ for crushed limestone.

Table 2. Sample type and dimensions related to each experiment.

\begin{tabular}{|c|c|c|c|}
\hline Influencers & Pull-off tests & Porosity measurements & Roughness \\
\hline Concrete removal & $\begin{array}{c}\text { Slabs of } 330 \mathrm{~mm} \times 330 \\
\mathrm{~mm} \times 200 \pm 5^{*} \mathrm{~mm} \\
/ 180 \pm 5^{* *} \mathrm{~mm}(\mathrm{CC}) \text { and } \\
300 \mathrm{~mm} \times 300 \mathrm{~mm} \times \\
100 \pm 5^{*} \mathrm{~mm} / 80 \pm 5^{* *} \mathrm{~mm} \\
(\mathrm{GC})\end{array}$ & $\begin{array}{l}\text { Cylinders of height } 100 \mathrm{~mm} \text { and } \\
\text { diameter } 100 \mathrm{~mm}(\mathrm{CC}) \text { for } \\
\text { capillary and water absorption. } \\
\text { For vacuum absorption, cylinders } \\
\text { of height } 20 \pm 3 \mathrm{~mm} \text { and diameter } \\
100 \mathrm{~mm}(\mathrm{CC})\end{array}$ & $\begin{array}{l}\text { Slabs of } 330 \mathrm{~mm} \times 330 \mathrm{~mm} \times \\
180 \pm 5 \mathrm{~mm}(\mathrm{CC}) \text { and } 300 \mathrm{~mm} \times \\
300 \mathrm{~mm} \times 80 \pm 5 \mathrm{~mm}(\mathrm{GC})\end{array}$ \\
\hline $\begin{array}{l}\text { Surface treatment } \\
\text { (singular and/or } \\
\text { combined } \\
\text { applications) }\end{array}$ & $\begin{array}{c}\text { Slabs of } 110 \pm 3 \mathrm{~mm} \times 330 \\
\mathrm{~mm} \times 200 \pm 5^{*} \mathrm{~mm} / \\
180 \pm 5^{* *} \mathrm{~mm}(\mathrm{CC}) \text { and } \\
110 \pm 3 \mathrm{~mm} \times 300 \mathrm{~mm} \times \\
100 \pm 5^{*} \mathrm{~mm} / 80 \pm 5^{* *} \mathrm{~mm} \\
(\mathrm{GC})\end{array}$ & $\begin{array}{l}\text { Cylinders of height } 100 \mathrm{~mm} \\
\text { and diameter } 100 \mathrm{~mm}(\mathrm{CC}) \\
\text { (only exposed to nano-silica } \\
\text { treatment) }\end{array}$ & \\
\hline
\end{tabular}

${ }^{*}$ and ${ }^{* *}$ indicate the thickness of the sample for the bond strength (where the concrete is covered with the repair mortar) and the surface tensile strength tests, respectively.

\subsection{Removal techniques}

Two removal techniques, jackhammering $(\mathrm{JH})$ and water jetting $(\mathrm{WJ})$ were employed in this study to 
remove $20 \pm 5 \mathrm{~mm}$ of the CC substrates. GC substrates only underwent jackhammering and the same height as for JH-CC was removed from JH-GC substrates. To remove $20 \pm 5 \mathrm{~mm}$ of the surface, a Hitachi H45MEY(35JR), $7 \mathrm{~kg}, 1150 \mathrm{~W}, 13.6 \mathrm{~J}$ was used for JH-CC and an Air Hammer model 29062 with the weight of $1.5 \mathrm{~kg}$ was used for JH-GC substrates. WJ with a high pressure of $100 \mathrm{MPa}$ was performed by the Crahay company in Belgium to remove the same depth of CC $(20 \pm 5 \mathrm{~mm})$. In general, the removal depth remained similar regardless of the removal technique.

\subsection{Application of nano-silica, bacteria and their combination}

Two techniques of pouring and spraying were applied for bacterial treatment and one (pouring) was utilized for nano-treatment. For the combined system (combination of bacterial and nano-treatment), both techniques were utilized. The surface treatment of samples was done according to the research performed by De Muynck et al. [31] on limestone at the Ghent University. However, adaptation of the procedure was necessary for the treatment of concrete samples. More explanations on each technique are given below.

\subsubsection{Pouring}

For the pouring application, the lateral surface of the samples (CC- and GC-slabs with dimensions given in Table 2 as well as CC cylinders of height $100 \mathrm{~mm}$ and diameter $100 \mathrm{~mm}$ ) was covered with aluminium foil tape which protruded up to $20 \mathrm{~mm}$ above the substrate surface to maintain the aqueous solution. Sample size and preparation was dependent on the test method, as mentioned in Section 2.2 and also later on in each related section. For each single treatment, the purpose was to cover the surface of the sample with at least $4 \pm 1 \mathrm{~mm}$ of the solution. For biodeposition treatment, the composition of the bacterial culture and nutrient was calculated by the volume of the space to fill up over the substrate surface (surface area $\left(\mathrm{mm}^{2}\right) \times 4 \pm 1 \mathrm{~mm}$ ). Each bacterial treatment contains around $85 \%$ nutrient solution $\left(\mathrm{CaCl}_{2}\right.$ and urea) and $15 \%$ bacteria suspension by volume, poured separately at once on the surface of the samples. Similar to the bacterial treatment, the weight of CNS (density $1.3 \mathrm{~g} / \mathrm{cm}^{3}$ ) for each treatment was calculated to fill the desired volume. Higher amounts were avoided because of the low porosity of concrete. When the concrete pores are saturated, the further precipitation occurs over the surface of the sample (shown in Figure 1), which was later brushed and removed (4 days after the application) with pressurized air. However, for the bacterially treated samples, a layer of $\mathrm{CaCO}_{3}$ was still observed after they were exposed to the pressurized air. For the combined application with bacterial culture and CNS, for each component the same amounts as in the singular application were poured on the surface at once. After $12 \mathrm{~h}$ the nutrient solution with $\mathrm{CaCl}_{2}(0.5 \mathrm{~mol} / \mathrm{l})$ and urea $(0.5 \mathrm{~mol} / \mathrm{l})$ was added in the same proportion to the bacterial suspension as in the singular application. The purpose was to allow the bacteria and the CNS to penetrate as deep as possible into the substrate before the nutrient solution was added.

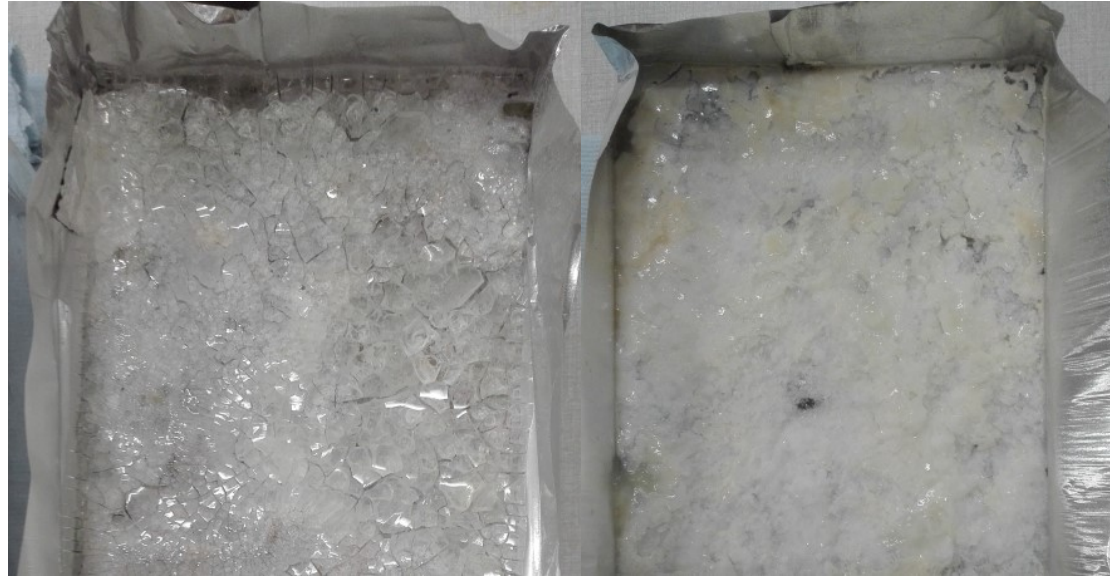

Figure 1. The plan view of dry silica gel layer for samples treated with CNS (left) and the combined application (right). 


\subsubsection{Spraying}

Four spray bottles $(400 \mathrm{ml})$ were used for the spraying application; one contained the nutrient solution with $\mathrm{CaCl}_{2}(1 \mathrm{~mol} / \mathrm{l})$ and urea $(1 \mathrm{~mol} / \mathrm{l})$, another one was filled with the bacterial suspension and the last two were filled with colloidal nano-silica (CNS) with and without the bacterial suspension. For the combined application, CNS and bacteria were mixed beforehand (concentration of each solution was identical to that of the pour-applied method) and applied in one spray. The spray-applied bacterial treatment was performed in 14 subsequent steps. In the first application, both bacterial and nutrient solutions were sprayed at once. Then, they were applied separately one after the other (starting with the nutrient) until the $10^{\text {th }}$ application where they both were applied. The application of the bacterial solution and the nutrient solution continued twice more separately (starting with the nutrient). The time span between each application was dependent on the moisture condition of the surface. Each time when the surface was in a saturated surface dry condition the next application was conducted. With regard to the combined application, the solution of CNS and bacteria together with that of the nutrients were applied first. Afterwards, the former solution was sprayed four more times. Between the $3^{\text {rd }}$ and the $4^{\text {th }}$ application, the nutrient solution was applied. Treatment continued with spraying both solutions three more times at once. In each application, solution(s) was (were) sprayed on each zone of the substrate surface to make sure the aqueous solution fully covers the surface area. The distance between the surface and the nozzle was $40 \pm 5 \mathrm{~mm}$. Spray nozzles were regulated in between the finest mist and a precise liquid jet. For the application of two spray bottles at once, nozzles were held next to each other and both solutions were sprayed at once in similar amounts (two spray applications per solution).

\subsection{Effect of removal techniques}

\subsubsection{Substrate surface characterization}

The following measurements were performed on the substrate surfaces after the removal of a certain depth of concrete $(20 \pm 5 \mathrm{~mm})$.

\subsubsection{Roughness}

Automated Laser Measurements (ALM) with an in-house developed apparatus were employed on the prepared CC and JH-GC surfaces to study the roughness value. Details regarding the equipment are given in $[1,32]$. For each concrete substrate ( $\mathrm{JH}$ and $\mathrm{WJ})$, the surface profile was obtained in $\mathrm{X}$-direction for 3 different Y-positions, and vice versa. The sampling length and the evaluation length were $40 \mathrm{~mm}$ and $280 \mathrm{~mm}$, respectively. The sampling length is taken shorter to separate the surface roughness from long wave components. Two CC slabs $(330 \mathrm{~mm} \times 330 \mathrm{~mm} \times 180 \pm 5 \mathrm{~mm})$ per surface preparation and two JH-GC samples ( $300 \mathrm{~mm}$ x $300 \mathrm{~mm} \times 80 \pm 5 \mathrm{~mm}$ ) underwent ALM analysis. They were each later on exposed to pull-off tests for surface tensile strength (STS) and bond strength analyses. Equations 1 and 2 were employed based on BS 1134 (2010) [33] to evaluate the $\mathrm{R}_{\mathrm{a}}$ (the centre-line roughness value $(\mathrm{mm})$ ) and the $\mathrm{R}_{\mathrm{q}}$ (the root-mean-square roughness value $(\mathrm{mm})$ ).

$$
\begin{aligned}
& R_{a} \approx \frac{1}{n} \sum_{i=1}^{n}\left|Z_{i}\right| \\
& R_{q} \approx \sqrt{\frac{1}{n} \sum_{i=1}^{n} Z_{i}^{2}}
\end{aligned}
$$

where $\mathrm{n}$ is the number of measurements, $\mathrm{i}$ is the measurement point number and $\mathrm{Z}$ is the amplitude $(\mathrm{mm})$. 


\subsubsection{Porosity}

Three different methods, capillary absorption, water absorption (including the gravity effect) and vacuum absorption were used to assess the porosity of the substrates after concrete removal. Three cylinders of height $100 \mathrm{~mm}$ and diameter $100 \mathrm{~mm}$ (per test method) were drilled from JH-, WJ-, and unprepared CC slabs for the water absorption and capillary absorption test. After performing these two tests, thinner cylinders of height $20 \pm 3 \mathrm{~mm}$ and diameter $100 \mathrm{~mm}$ were sawn containing the prepared surface for vacuum tests (see Figure 2). The goal was to focus on the superficial layer of substrates, where the largest impact of removal techniques occurs. Similar procedure as explained in [1] was followed to perform capillary absorption and vacuum tests. For the vacuum absorption test, samples were evacuated in a vacuum chamber for $2 \mathrm{~h}$ and were subsequently soaked in water for $24 \mathrm{~h}$. At this step, the saturated mass in air was measured. Then, the mass was measured while the samples were immersed in water. Afterwards, they were oven dried at $40^{\circ} \mathrm{C}$ till the mass change between the two measurements in $24 \mathrm{~h}$ was less than $0.1 \%$. The water absorption under vacuum was calculated by dividing the difference between the saturated mass in the air and the dry mass, by the difference between the saturated mass in the air and in the water. Capillary absorption test was performed by the immersion of dry samples $(5-6 \mathrm{~mm})$ in water. Water absorption was done in the opposite direction to the capillary absorption in such a way that the prepared surface of the substrate was placed upside and each time 120 $\mathrm{ml}$ water was poured on the surface. Before pouring the water, edges of samples were covered with aluminium foil tape which protruded up to $20 \mathrm{~mm}$ above the substrate surface for the maintenance of the water. For very rough surfaces, the positioning of the samples for the performance of a capillary absorption test is very hard as they need to be placed with their prepared surface into water. The same equation and time frame as for the capillary absorption test was utilized for the water absorption. Every $5,15,30,60,120,180$ and 240 minutes water was removed, samples were weighed and the absorption (I) was calculated as follows:

$$
I=\frac{m_{t}}{a^{*} d}
$$

where $\mathrm{I}(\mathrm{mm})$ is the absorption, $\mathrm{m}_{\mathrm{t}}(\mathrm{g})$ is the change in the mass at time $\mathrm{t}, \mathrm{a}\left(\mathrm{mm}^{2}\right)$ is the exposed area and $\mathrm{d}\left(\mathrm{g} / \mathrm{mm}^{3}\right)$ is the density of the water [34].

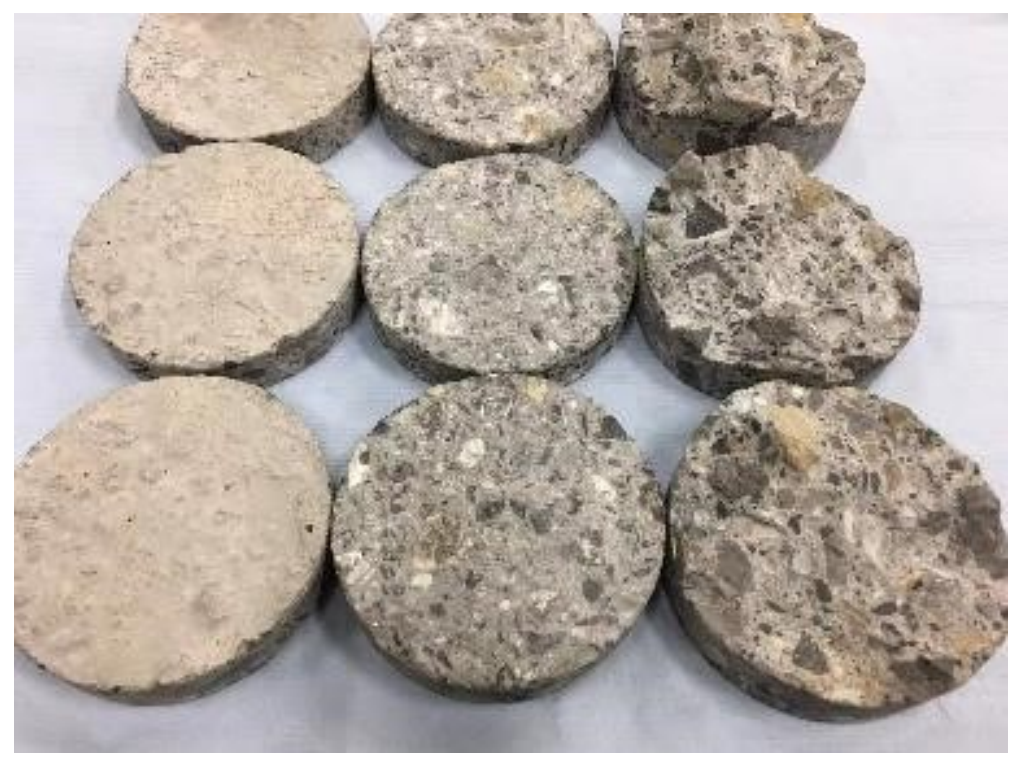

Figure 2. Prepared thin samples of CC for vacuum absorption test.

\subsubsection{Surface tensile strength (STS)}

Adhesion between the existing concrete and the repair material is not only dependent on the properties of the overlay, but it also depends on the substrate quality after the removal of deteriorated concrete. To 
study the quality of concrete at the superficial layer, surface tensile strength (STS) tests were employed on the CC and GC substrates. Five pull-off tests were performed according to EN 1542 [35] on JH-, WJ-, and unprepared CC slabs (age of 3 month or older) and 6 on JH-GC samples (age of 1 year or older). Cores with a diameter of $50 \mathrm{~mm}$ were drilled into the substrate until a depth of $15 \mathrm{~mm}$ and then a metal dolly with a diameter of $50 \mathrm{~mm}$ was glued with epoxy resin to the core. Testing was performed $24 \mathrm{~h}$ after gluing by using an automatic bond strength device type Proceq DY-2 with a maximum tensile force up to $16 \mathrm{kN}$ and a calibrated accuracy of $1 \%$ on the measurements.

The surface tensile strength $\left(\mathrm{f}_{\mathrm{hs}}\right)$ was calculated using the following equation (4):

$$
f_{h s}=\frac{4 F_{h}}{\pi D^{2}}
$$

where $f_{h s}$ is the surface tensile strength $\left(\mathrm{N} / \mathrm{mm}^{2}\right), F_{h}$ the failure load $(N)$ and $D$ the mean diameter $(\mathrm{mm})$.

\subsubsection{Adhesion}

Bond strength between the existing concrete and the repair material was studied based on NBN EN 1542 [35]. CC substrates after WJ and JH were covered with repair mortar (thickness $15 \pm 5 \mathrm{~mm}$ ). 28 days after the application of the repair mortar (MasterEmaco S5400) 5 pull-off tests were employed, except for JH samples, for which 8 tests were performed on two slabs. Bond strength of one CC slab that was not exposed to any removal technique and had a smooth surface (unprepared) was also studied. In general, there were 5 replicates for WJ-CC and unprepared CC substrate surfaces, and 8 for JH-CC slabs. To assess the durability of the bond between the unprepared or prepared $\mathrm{CC}$ substrates and the repair mortar three pull-off tests (per slab) were employed after 12 months on the same samples as tested after 28 days. In terms of JH-GC slabs, one slab underwent three pull-off tests. The same repair mortar with the same thickness as for $\mathrm{CC}$ substrates was overlaid on the GC slab. The following equation (5) as given in NBN EN 1542 [35] was employed to measure the drilling depth for the pull-off test:

$$
d_{i}=d_{d}+(15 \pm 5)
$$

where $d_{i}$ and $d_{d}$ are the total drill-in depth and the thickness of the mortar layer in mm, respectively.

\subsection{Effect of surface treatments}

\subsubsection{Nano-silica and biodeposition characterization}

X-Ray Diffraction (XRD) and Scanning Electron Microscope-Energy Dispersive X-Ray Spectroscopy (SEM-EDX) were used to investigate the activity of the bacteria and the composition of the precipitated layer. To this end, the precipitated layer was scraped from the surface of a pour-applied bacterially treated sample and the resulting powder underwent the analysis. This was not conducted for the sprayapplied samples as no layer of $\mathrm{CaCO}_{3}$ was observed at the surface of samples treated with this method. XRD was also applied on the powder of the nano-silica crystals scraped from the surface of a treated sample. Powder samples were stored in a vacuum environment until the day of XRD and SEM-EDX experiment.

\subsubsection{Adhesion}

Repair mortar was applied on JH-CC and -GC slabs 7 days after the surface was treated with each treatment method. The thickness and type of repair mortar as well as the test methodology is given in Section 2.5.2. Six replicates for CNS-pouring on CC samples, and for the rest 3 replicates per concrete composition and treatment technique were performed.

\subsubsection{Surface characterization}

The best treatment according to the bond strength results was selected for porosity and surface tensile strength measurements. The purpose was to study the influence of the optimal treatment method on the substrate properties. Capillary absorption test was performed as explained in Section 2.5.1.2 on CNStreated CC samples with three replicates. STS measurements were performed on both CNS-CC and - 
GC samples with 5 and 3 replications, respectively. Experiments were performed at least 7 days after the day of treatment as explained in Sections 2.5.1.2-3.

\subsection{X-ray diffraction $(X R D)$ analysis}

XRD was performed on crystals of the bacterial precipitated calcite layer and the nano-silica. An ARLTM X'TRA Powder Diffractometer of Thermo Scientific was used for the measurements. A copper X-ray tube was utilized for the XRD analysis with a wavelength of $0.154 \mathrm{~nm}$; Cu K-shell levels are equivalent to the wavelength $(0.154 \mathrm{~nm})$. Scanning was recorded at an interval of $5^{\circ}$ to $70^{\circ}$ two-theta. The step size and measuring time were $0.02^{\circ}$ and $1 \mathrm{~h} 20 \mathrm{~min}$, respectively.

\subsection{Scanning electron microscopy (SEM)}

For SEM analysis, a part of the biodeposition layer was scraped from the surface of a pour-applied bacterially treated sample. SEM analysis was carried out on an instrument equipped with an EnergyDispersive X-ray analyser (EDX detector) and operating at an acceleration voltage of $20 \mathrm{kV}$.

To study the quality of the adhesion between the substrate and the repair material, two cylinders of height $200 \mathrm{~mm}$ and diameter $50 \mathrm{~mm}$ were drilled from each of the two repaired slabs of JH-CC and JHCC treated with CNS samples. Afterwards, each cylinder was first sawn from the bottom and then vertically from the middle as shown in Figure 3. One half of each cylinder was selected and then perpendicular to the interface a small sample of $15 \mathrm{~mm} \times 15 \mathrm{~mm} \times 10 \mathrm{~mm}$ was cut containing the interfacial layer between the substrate and the repair mortar, see Figure 3. In total, two samples per composition underwent SEM analysis to ensure the reproducibility of the results. These samples were first oven dried for $12 \mathrm{~h}$ and then subjected to a carbon coating process to have a good electrical conductivity.

\section{$(50 \mathrm{~mm} \times 200 \mathrm{~mm})$}

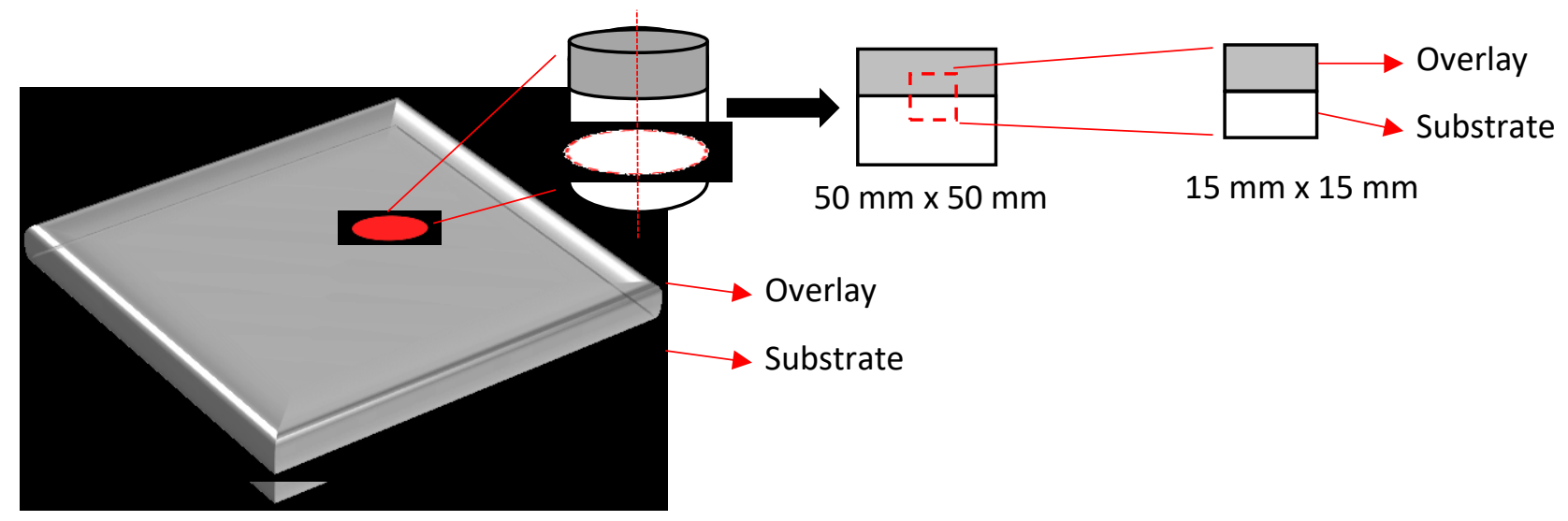

Figure 3. Schematic view of the slab $(330 \mathrm{~mm} \times 330 \mathrm{~mm}$ x $200 \pm 5 \mathrm{~mm})$ and the preparation of the interface for the SEM-EDX analysis. Dashed lines show the cut line.

\subsection{Statistical analysis}

Statistical analysis was performed on all test results using SPSS Statistics 25. One-Way analysis of variance (ANOVA) was carried out, followed by multiple comparisons of means by a Tukey test to assess the statistical significance of the difference between the means. At the end, those means with the propability values ( $\mathrm{p}$-values) less than 0.05 were considered significantly different. 


\section{Results and discussion}

\subsection{Roughness}

Figure 4 presents the roughness created at the substrate surface by each removal technique. A similar trend is observed for both the $\mathrm{R}_{\mathrm{a}}$ (the arithmetic average deviation of the absolute values of the profile heights from the centre line) and the $\mathrm{R}_{\mathrm{q}}$ (the root-mean-square roughness value). Results shown in the Figure are the average values of the ALM measurements in $\mathrm{X}$ and $\mathrm{Y}$ direction achieved from two samples per concrete composition and surface treatment. According to Figure 4, WJ led to a much larger roughness compared to $\mathrm{JH}$. This has also been reported in other publications [1,2]. Yazdi et al. [1] reported the importance of the test method to compare the surface roughness of concrete mixtures exposed to concrete removal techniques such as water jetting or jackhammering. It was found that the sand patch test in comparison with the ALM test was not accurate enough to show the difference between the surface roughness of the studied mixtures exposed to gritblasting, WJ and JH techniques. Based on the statistical analysis, the difference in the roughness caused by different removal techniques is significant. However, when the JH-CC is compared with the JH-GC an insignificant difference is observed. There is a misconception over the influence of roughness on the pull-off test results. Although, it might be in general expected that surface roughness will improve the bond strength, some publications $[1,4,36]$ have reported the ineffective role of surface roughness on the tensile bond strength. The authors think that the influence of roughness is highly dependent on the state of stress applied during the bond experiment. Further explanation in this regard is given in section 3.4.

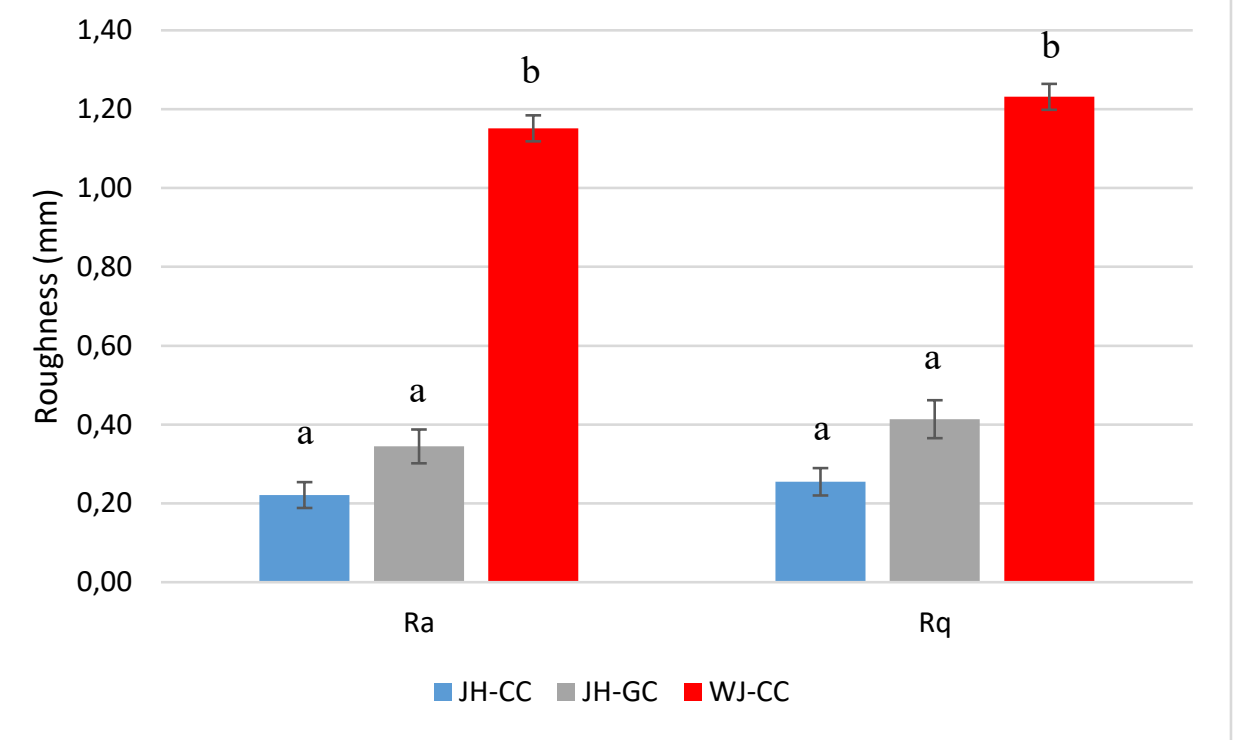

Figure 4. Roughness of $\mathrm{CC}$ and JH-GC substrates after concrete removal. Error bars represent the standard error. Means with the same letter indication are not significantly different. $R_{a}$ is the centre-line roughness value and $\mathrm{R}_{\mathrm{q}}$ is the root-mean-square roughness value.

\subsection{Porosity measurements}

Three different test methods were employed to study the porosity of the substrate after the removal of a $20 \pm 5 \mathrm{~mm}$ concrete layer. The capillary absorption of samples was studied and the results are given in Figure 5. Moreover, Figure 5 indicates the water absorption of samples with the consideration of the effect of gravity. As shown in Figure 5, the influence of removal techniques on the capillary and water absorption of samples was negligible. Baltazar et al. [11] achieved different water absorption results on samples with different $\mathrm{w} / \mathrm{c}$ ratios. For those with a higher $\mathrm{w} / \mathrm{c}$ ratio, a lower impact of surface preparation on the absorption rate was observed. The similarity between the results shown in the Figure reveals the insignificant effect of gravity on the water uptake of concrete substrates. Additionally, it validates the application of the latter method, introducing a more convenient test method compared to the capillary test, namely for samples with large aggregate size and roughness, e.g. WJ-CC. The impact of porosity at the meso-interphase zone (layer of 1-2 mm thickness at the interfacial zone) and the upper zone of 
the substrate has been reported in [37]. Their results indicate that an increase in the porosity of the former zone will decrease the bond strength between the substrate and the overlay. In contrast, the bonding was increased with an increase in the porosity of the upper zone of the substrate.

\section{Capillary absorption}
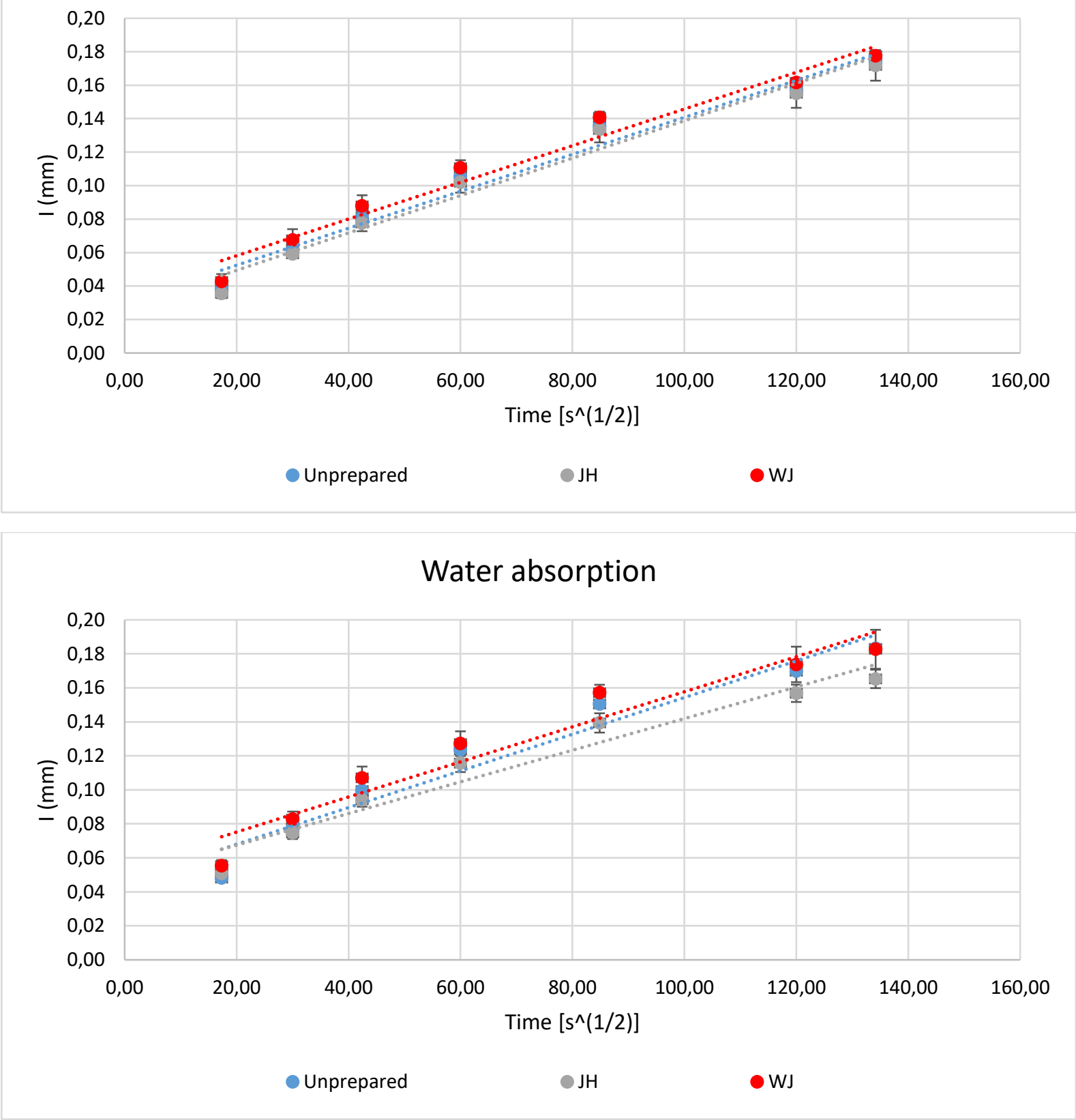

Figure 5. Capillary and water absorption of $\mathrm{CC}$ substrates. Error bars represent the standard error.

As the superficial layer of the substrate is highly affected by the removal technique, in this study the open porosity of this zone has comprehensively been investigated by the vacuum absorption test. Open porosity results given in Figure 6 clearly show that $\mathrm{JH}$ in comparison with the unprepared sample achieved a significantly lower open porosity. However, when WJ is compared with JH or the unprepared sample the difference is insignificant. A slight influence of removal techniques on the water absorption of substrates was reported in [38] when WJ was compared with sandblasting. According to their results, WJ induced a higher rate of absorption than SB due to the creation of microcracks at the superficial layer of samples. Moreover, in the results given in [1] it was observed that WJ- and JH-CC had a similar water uptake. Courard et al. [39] studied the water absorption and open porosity of sandblasted and polished concrete slabs and achieved a negligible difference induced by the surface preparation on the 
test results. In general, when removal techniques from the same classification [1] are compared, it appears that they do not change the porosity of substrates significantly. Moreover, based on the publications $[1,11,38]$ and the results of this study one could express that the influence of surface preparation on the permeability of the existing concrete might be dependent on the microstructure (e.g. porosity) and mix composition (e.g. aggregate size and shape) of the concrete.

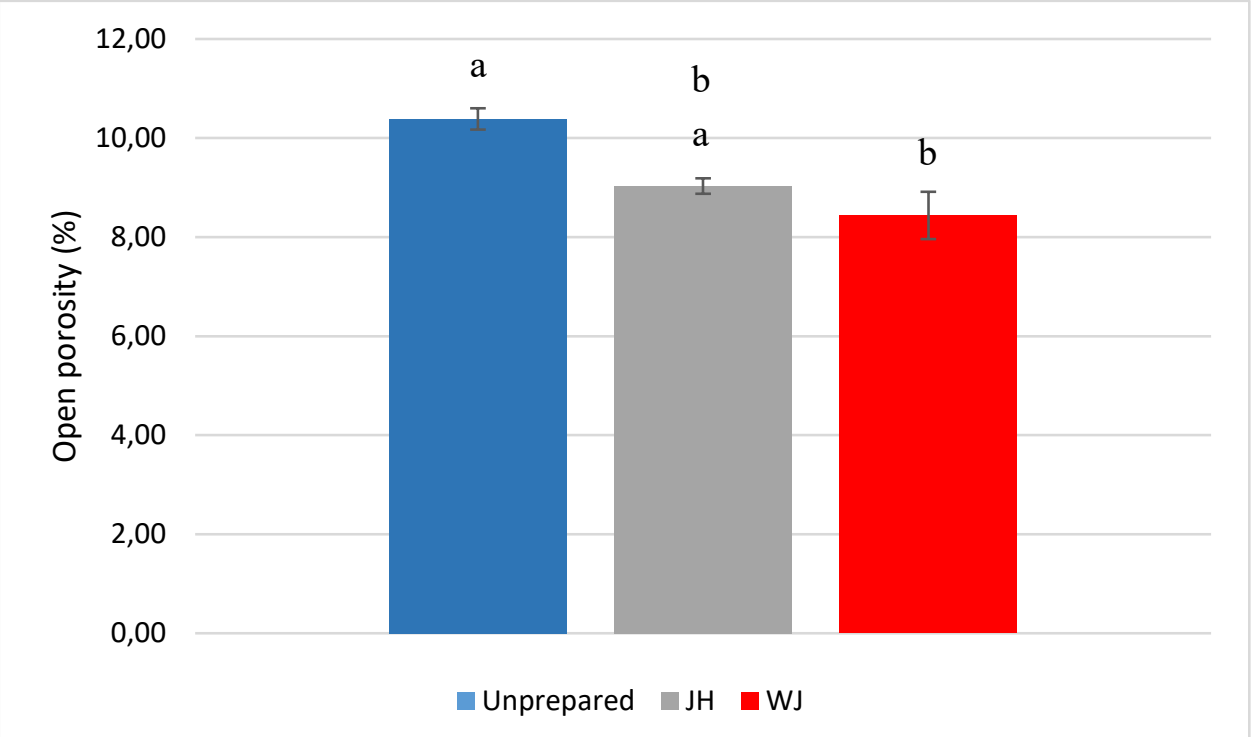

Figure 6. Open porosity of CC substrates. Error bars represent the standard error. Means with the same letter indication are not significantly different.

\subsection{Surface tensile strength}

Figure 7 expresses that the highest average value of the surface tensile strength (STS) was obtained when the sample was not exposed to any removal technique. WJ and JH samples achieved lower STS compared to unprepared samples. Statistical analysis indicates the insignificant difference between the STS of unprepared and WJ samples. However, the difference between JH and WJ or the unprepared sample was significant. The reduction in the STS of JH samples has been reported in other publications $[1,3]$ and is attributed to the microcracks created during the removal. Figure 8 shows an example of failure modes for different samples under STS testing. For JH substrates, $100 \%$ of the failures occurred at the superficial layer (an example is shown in Figure 8), this number is $20 \%$ for WJ samples. Failures in the unprepared slab were quite similar to WJ. What differentiates the failure modes of WJ and JH from each other is the fact that for the former (WJ), failures are mainly irregular and occur at the interfacial transition zone (ITZ) between aggregates and binder. It is also the same for samples with an unprepared surface. However, JH failures are at the subsurface of the substrate in the aggregates and binder damaged during the $\mathrm{JH}$. Yazdi et al. [1], claimed that the irregularity in the failure mode is dependent on the aggregate size apart from the removal technique. The results of this section confirm the necessity of studying the STS of concrete substrates after application of removal techniques as it clearly shows the impact of the removal techniques on the old concrete. 


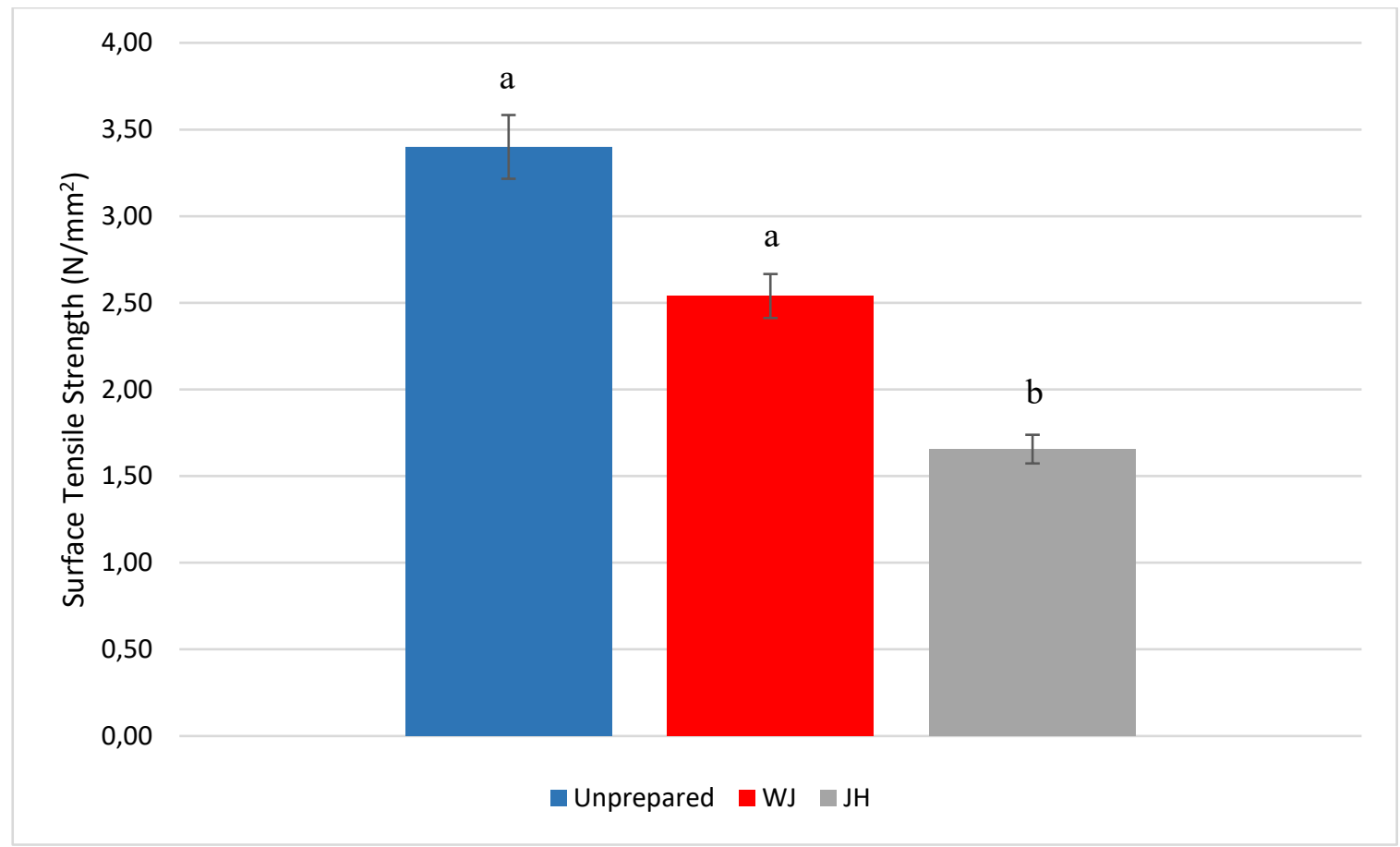

Figure 7. Surface tensile strength results of CC samples. Error bars represent the standard error. Means with the same letter indication are not significantly different.

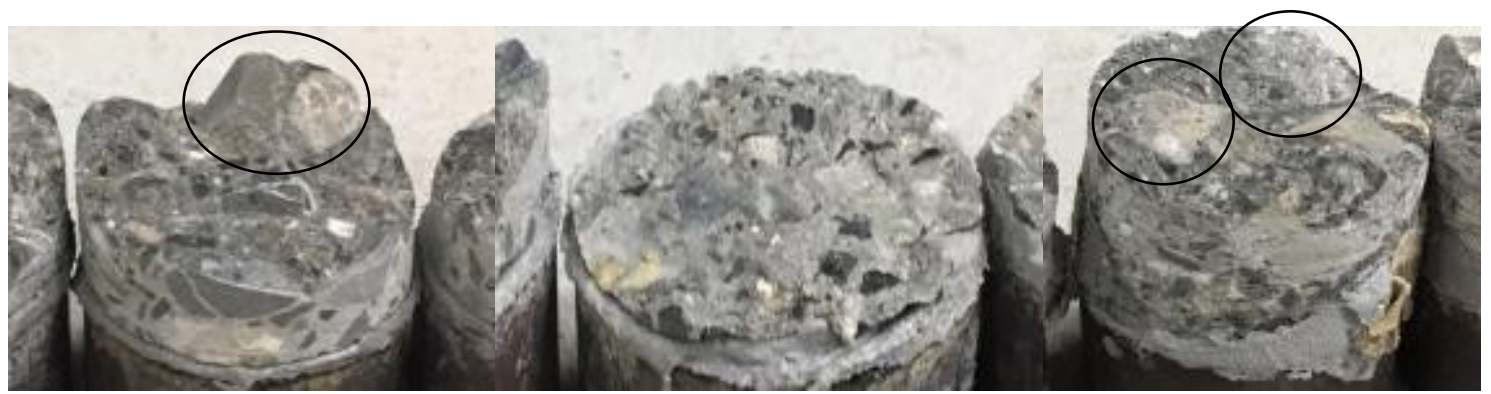

Figure 8. Example of failure modes of unprepared-CC (left) JH-CC (middle) and WJ-CC (right) substrates under STS testing. The encircled zones show failures at the interfacial transition zone (ITZ).

\subsection{Bond strength - effect of removal techniques}

The bond strength results are shown in Figure 9. Interestingly, the unprepared substrate with a smooth surface achieved the highest bond strength in comparison to other substrates, showing the ineffectiveness of roughness for pull-off experiments. Grit blasted samples with a much lower roughness $\left(\mathrm{R}_{\mathrm{a}}: 0.21 \mathrm{~mm}\right)$ compared to WJ samples $\left(\mathrm{R}_{\mathrm{a}}: 1.52 \mathrm{~mm}\right)$ obtained a higher bond strength in the results given in $[1,40]$. Some researchers have introduced the surface roughness of sandblasted substrates as the threshold value when the state of the stress in the experiment is tensile [4]. Bond tests have shown not only in this study but also in other studies $[1,4,36,41]$ that surface roughness only has a minor influence on the pull-off test results. The authors believe that the effect of surface roughness is mainly dependent on the state of stress applied during the bond test, therefore, it is dependent on the bond test method. For example, if tensile bond strength is employed, the effect of roughness is negligible, while if the shear bond strength test is done the effect is expected to be higher. This statement has also been supported in other studies [41, 42]. Snoeck et al. [30] performed slant shear tests and revealed the advantage of roughness in the improvement of the bond strength between old and new mortars.

Based on the results, one may express the influence of the surface preparation (roughness) on the durability of the bonding in layered composites. It is consistent with the findings of Talbot et.al [5]. With the comparison of the results achieved after 28 days with those of 12 months, a slight and insignificant reduction in bond strength is observed for unprepared and $\mathrm{JH}$ samples. However, WJ substrates achieved a higher bond strength by $7 \%$, although this difference was also not statistically significant. 
Given the results of this study and other studies on removal techniques, $\mathrm{JH}$ has shown to give a bonding of $0.9-1 \mathrm{MPa}[3,5,40]$ and $\mathrm{WJ}$ has shown to result in a bonding of 1.8-2 $\mathrm{MPa}[1,40,41]$. Nevertheless, it should be mentioned that the bond strength value may vary depending on the concrete composition, removal energy, etc. In this study, both JH-CC and -GC achieved an adhesion between 0.9 MPa and 1 $\mathrm{MPa}$, confirming the reproducibility of the results. The low adhesion between the JH substrates and the repair material has been attributed to the damage that occurred to the subsurface of the existing concrete during the removal process [3]. Some researchers have proposed high-pressure water or sandblasting techniques to compensate the lost bond caused by the $\mathrm{JH}[4,5]$, however, they are both time-consuming and economically expensive, and also the latter in particular is not environmentally friendly. Talbot et al. [5] reported an increase of $12 \%$ in the bond strength of JH substrates when they were subsequently sandblasted.

Concerning the failures shown in Figure 10, for unprepared samples (28 days) 80\% (4/5) of ruptures were adhesive failures, occurring at the interlayer. Failures were $100 \%$ at the interlayer for these samples after 12 months. For JH samples (28 days and 12 months) almost all failures happened at the subsurface of the old concrete (close to the interface), also considered as adhesive failure. However, cohesive rupture was observed for $80 \%$ of $\mathrm{WJ}$ samples (28 days and 12 months) with failures deeper in the substrate. The influence of the roughness and removal techniques on the pull-off failure modes was explained in [1]. It was also reported that failures of WJ samples are mainly at the interfacial transition zone of aggregates and cement paste in the substrate.

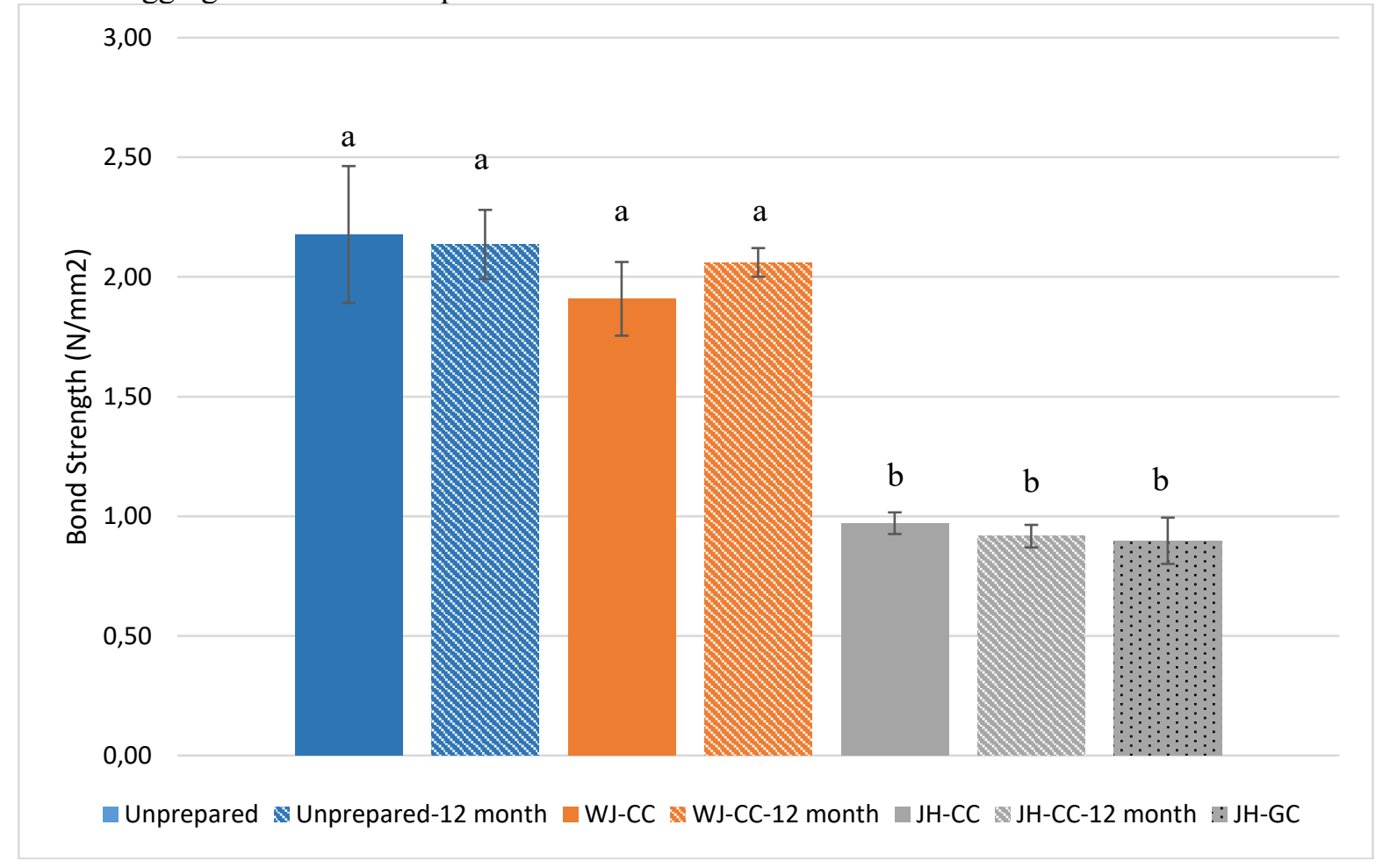

Figure 9. Bond strengths results. Error bars represent the standard error. Means with the same letter indication are not significantly different.

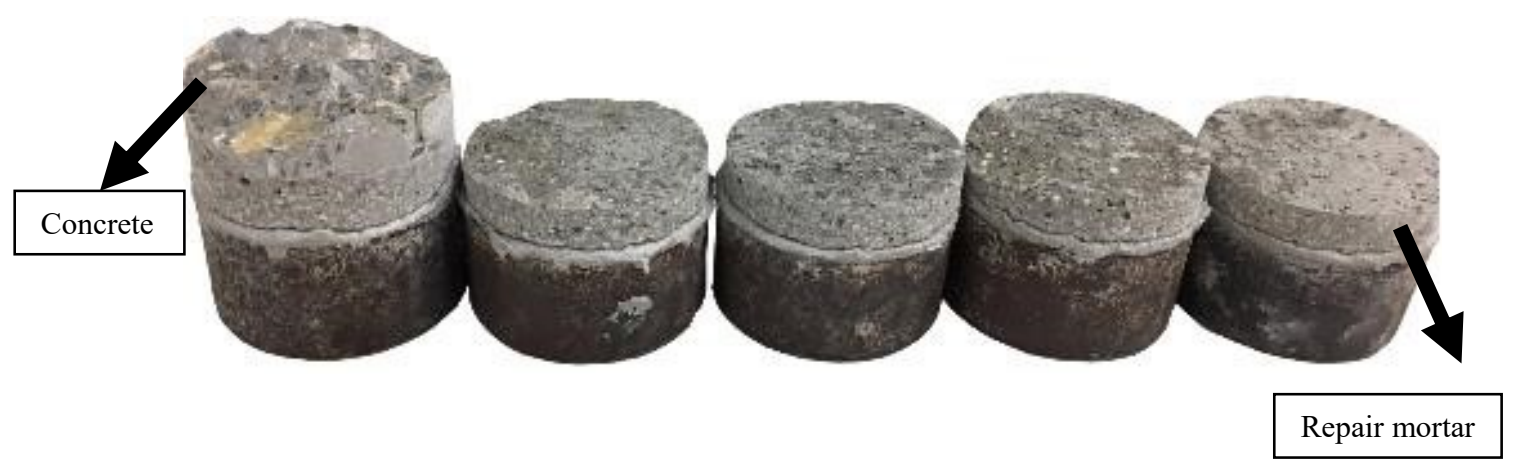




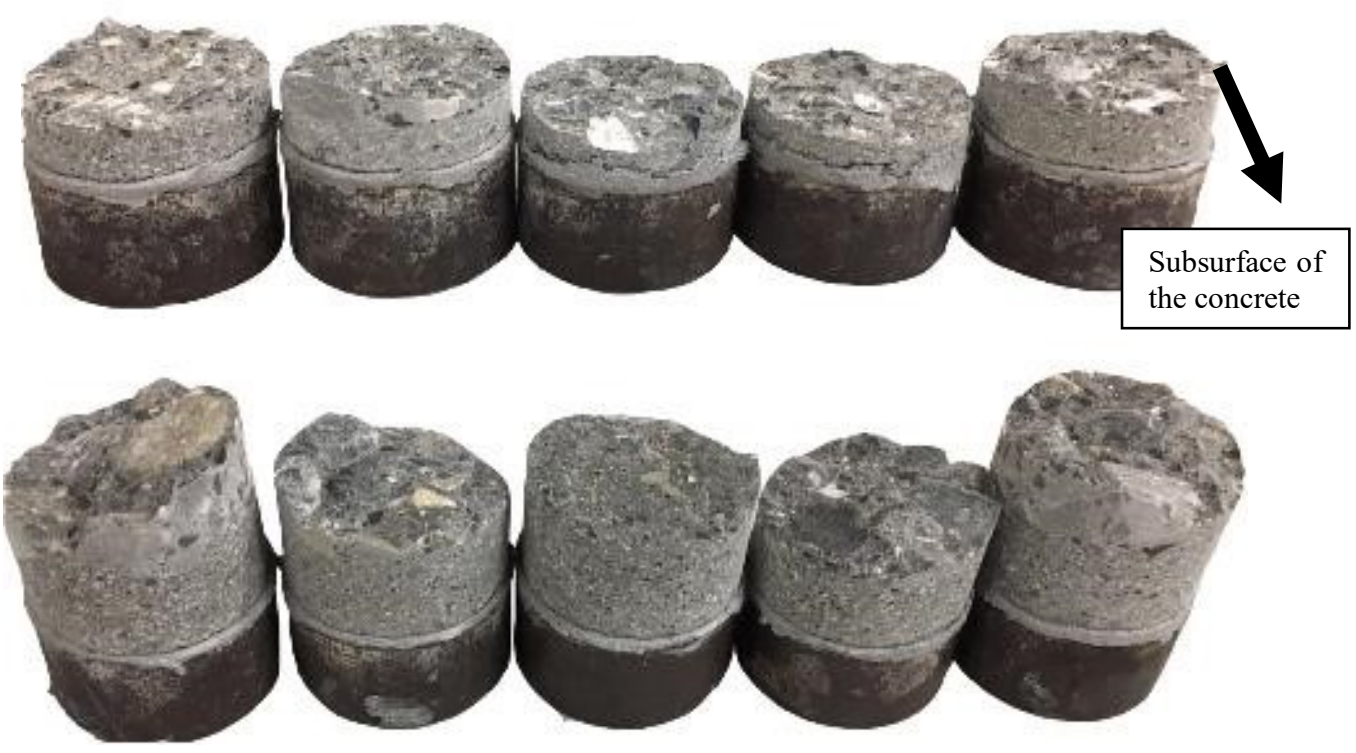

Figure 10. Bond strength failure modes of unprepared-CC (top) JH-CC (middle) and WJ-CC (bottom) samples at 28 days.

\subsection{Characterization of treatment materials}

Biodeposited crystals were scraped off the surface of a pour-applied bacterially treated sample for microstructural analysis. Figure 11 shows the SEM image and its corresponding EDX spectrum of the deposited crystals. One can see that carbon, oxygen and calcium are present in large amounts which implies the precipitation of $\mathrm{CaCO}_{3}$ crystals during the bacterial activation. An example of the deposited products is given in Figure 12. As shown, flower-, cube- and sphere-shaped crystals are present (see Figure 12). The mineralogical composition was analyzed using XRD and the results are given in the spectrum of Figure 13. XRD results show the existence of calcite and vaterite and SEM images shown in Figure 12, confirm their presence. Calcite and vaterite are known to have cubic, and flower and sphere morphologies, respectively [43].

An important aspect of this analysis is the fact that the bacteria were able to produce large amounts of carbonate crystals. The imprints left behind by the bacteria in the crystals are the evidence of this process, see Figure 12. The black dots on the spherical crystals show the bacterial involvement in the carbonate precipitation $[25,44]$.

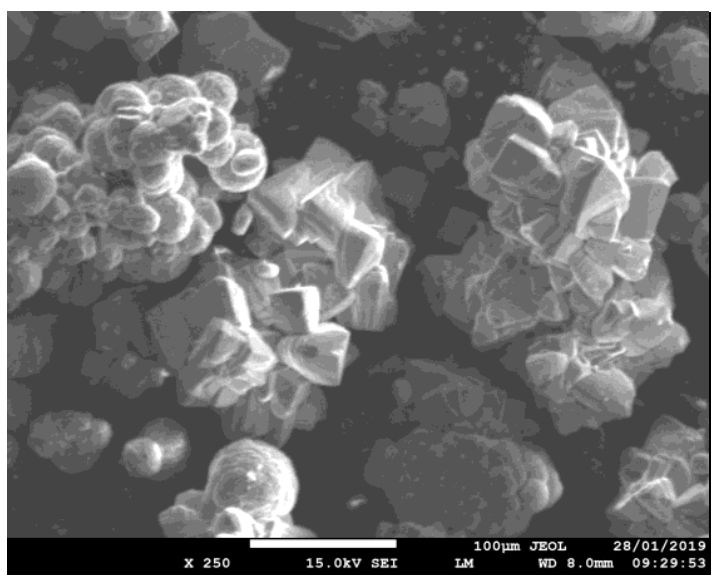




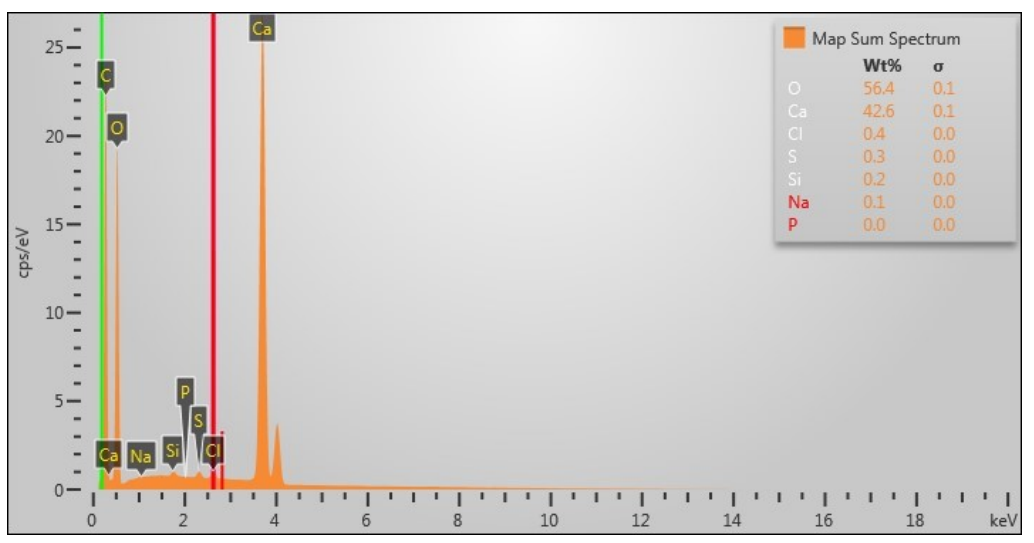

Figure 11. SEM (top) and EDX (bottom) taken from powder of biodeposited layer. Scale bar equals $100 \mu \mathrm{m}$. Xaxis and $\mathrm{Y}$-axis indicate kilo-electron-volt $(\mathrm{KeV})$ and counts per second per electron-volt (cps/eV), repectively.
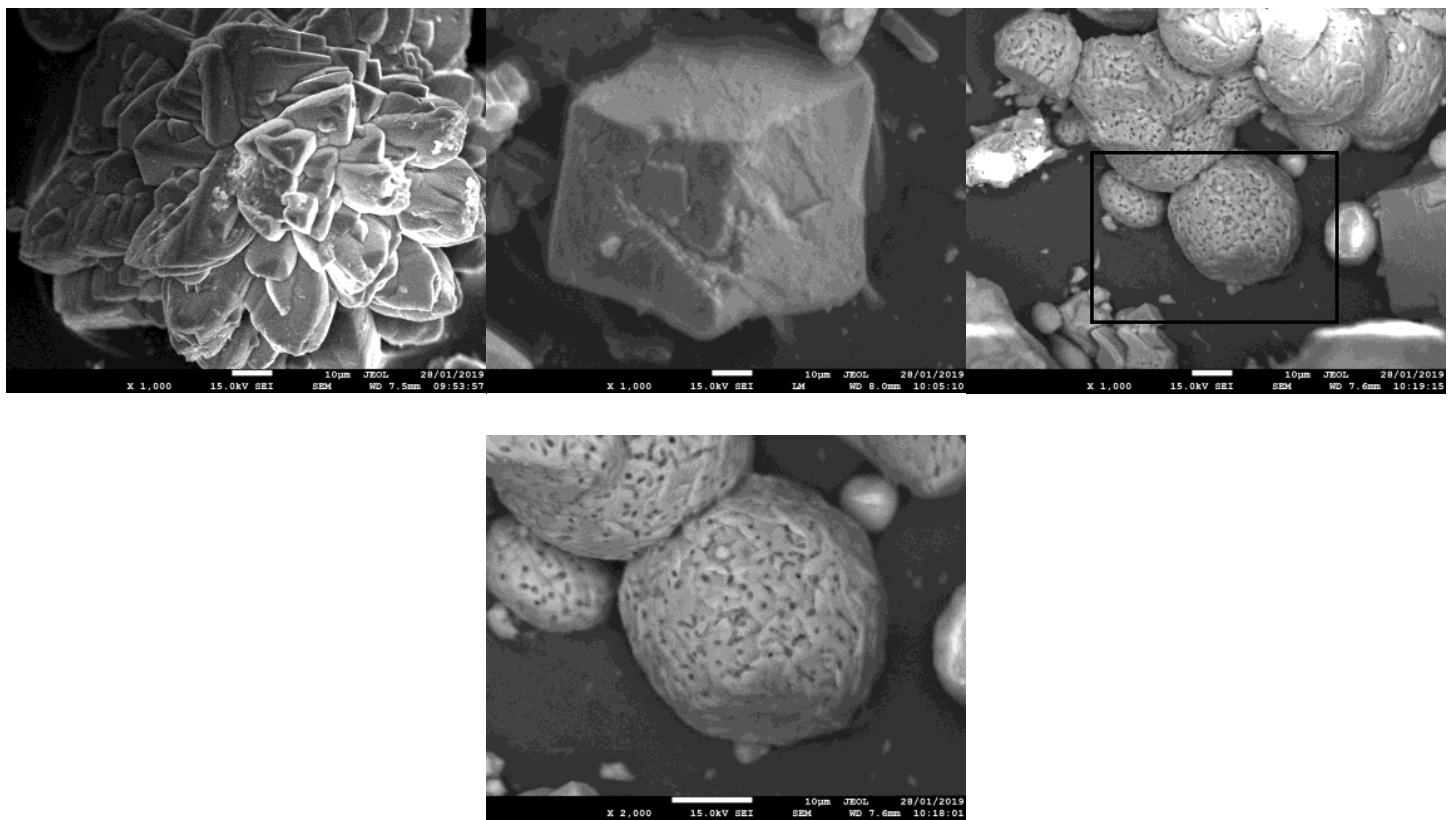

Figure 12. Flower-, cube- and sphere-shaped crystal formations respectively from left to right. The image at the bottom is a magnification of the zone in the black square. Scale bars equal $10 \mu \mathrm{m}$.

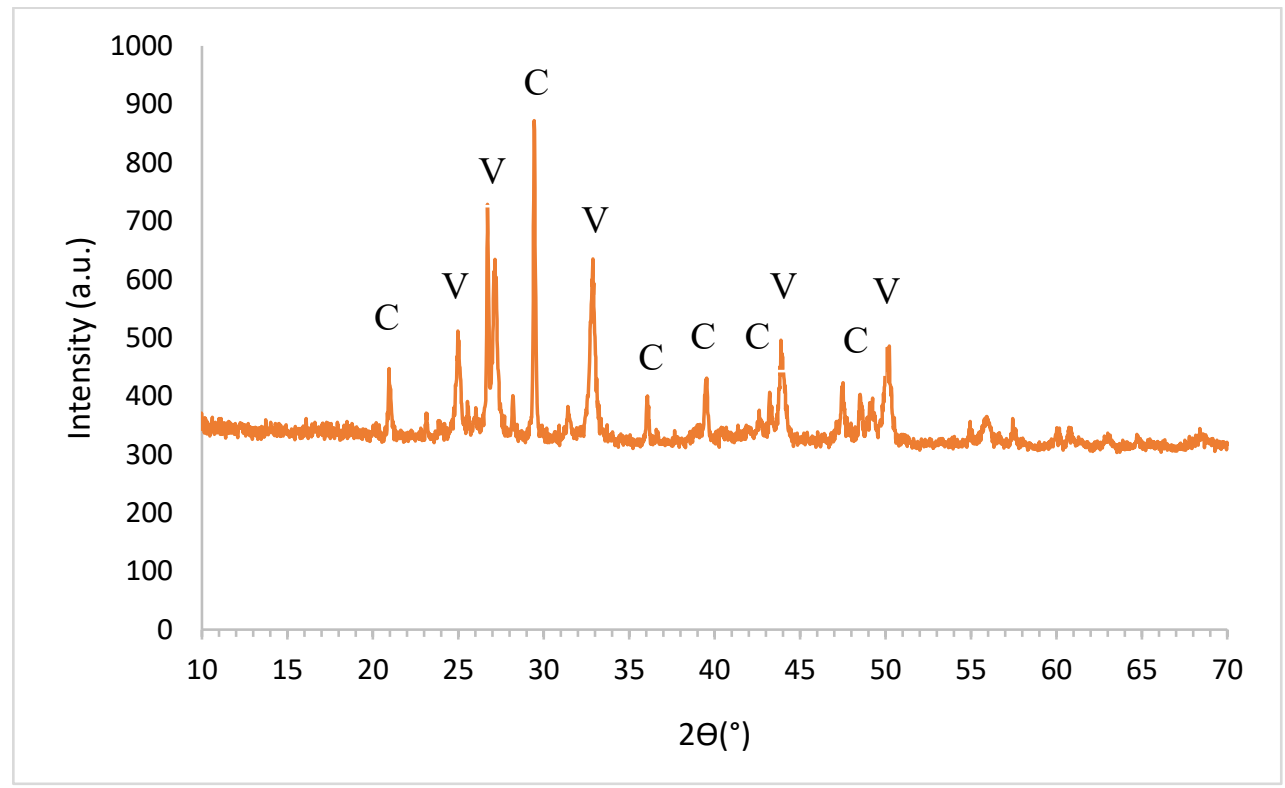


Figure 13. XRD pattern of the crystal formations induced by the biodeposition. $\mathrm{C}$ and $\mathrm{V}$ stand for calcite and vaterite, respectively.

The XRD pattern of a scraped CNS layer is shown is Figure 14. Similar to the characterization of samples treated with bacteria, crystals from the surface of a CNS-treated sample were scraped for XRD analysis. As shown in Figure 14, CNS has an amorphous structure exhibited by the large hump between $13^{\circ}-40^{\circ}$. Therefore, it possesses a high potential to react with the reaction products of concrete such as $\mathrm{Ca}(\mathrm{OH})_{2}$ and also influences the hydration of cementitious materials.

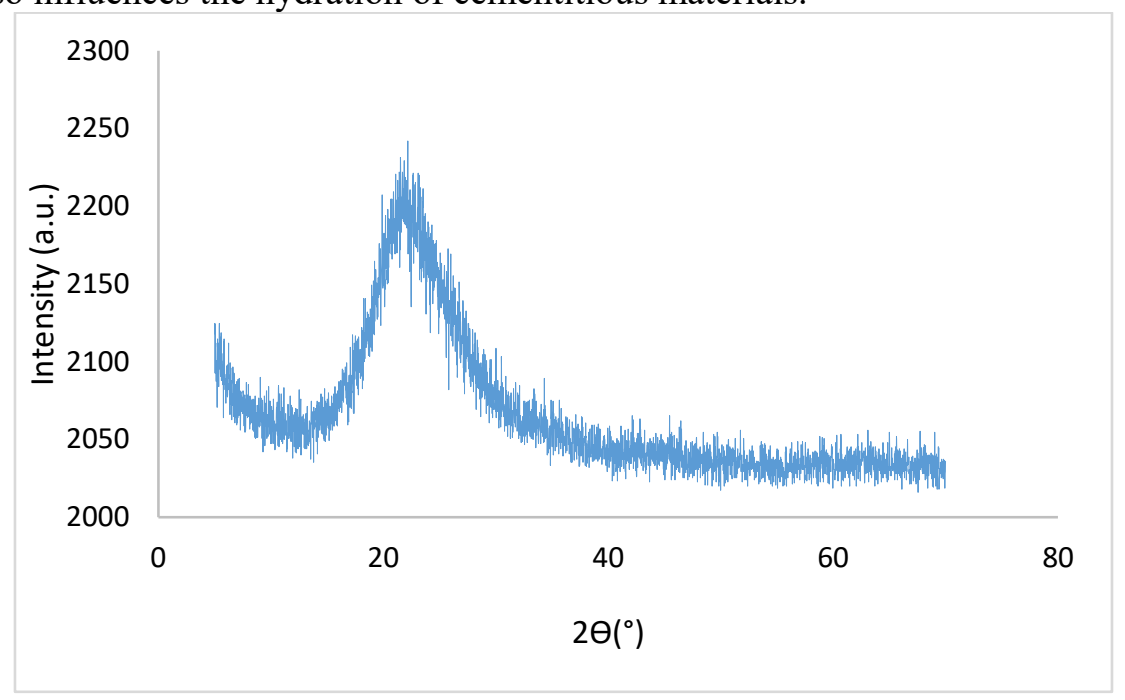

Figure 14. XRD pattern of CNS crystals.

\subsection{Bond strength improvement - effect of biodeposition and nano-materials}

The main goal of this section is to propose an effective solution to restore the lost bond strength of the $\mathrm{JH}$ substrate. Bond strength results of the JH samples and those treated with single and combined surface treatments are given in Figure 15. Different methods of application (pouring and spraying) were tried for the bacterial treatment and the combined mix. In terms of the single bacterial treatment, as shown, the spraying application gives a larger bond strength compared to the treatment with poured bacteria. Bacteria-pouring is not shown in the Figure as the repair mortar came off during drilling of cores before the performance of the pull-off test (Figure 16), therefore, the bond strength of zero was considered for these samples. The difference in the results of spray- and pour-applied bacterial treatment might be because of the presence of a thin $\mathrm{CaCO}_{3}$ layer precipitated at the surface of samples when the latter application was employed. This layer acts as a bond-breaker and therefore weakens the bond between the layers. As mentioned in section 2.4.1, the exposure of pour-applied bacterially treated samples to the pressurized air did not lead to the full removal of the $\mathrm{CaCO}_{3}$ layer from the surface. Two potential zones of weakness are created with the existence of the $\mathrm{CaCO}_{3}$ layer: at the interfaces of this $\mathrm{CaCO}_{3}$ layer with the substrate and the repair mortar. Moreover, the calcium carbonate layer has a low tensile strength and has the risk of cohesive failure within the precipitated layer itself. The authors' suggestion is to avoid the creation of an extra interface between the old and the new layer. This issue has also been reported in some studies conducted on bonding agents in repair systems. Some researchers claimed that bonding agents start to deteriorate the bond when a layer of the agent is created on the substrate $[45,46]$. However, results show that with the elimination of this layer through the application of the spray-method the bond is improved remarkably. The impact of concrete carbonation on the bond strength of sandblasted and jackhammered samples was investigated in [41]. According to the results, accelerated carbonation during 2.5 months reduced the bond strength of the latter samples by $16 \%$ and did not influence the adhesion of the former samples. The more detrimental impact of carbonation on JH samples compared to sandblasted samples was attributed to the microcracks or any other defects in the subsurface of the substrate which lets carbon dioxide easily access through the concrete surface. This can create a dense and soft surface layer, and act as a pore-blocker, decreasing the chemical ion exchange between the substrate and the repair material. Yazdi et al. [1] reported a higher microcrack density at 
the superficial layer of JH substrates compared to grit blasted substrates. Champa et al. [47] exposed the contact surface of a group of concrete samples after SB to the laboratory air for several days. They reported a reduction in the bond strength between $\mathrm{Mg}-\mathrm{NH}_{4}-\mathrm{PO}_{4}$ type of repair mortar and concrete caused by the production of fizzing at the interface. They explained it as such that this type of mortar possesses a low $\mathrm{pH}$ level in the early time of hydration and so when the acidic phase reacts with the carbonation layer a significant fizzing is produced. As a result, bubbles are formed at the interface, reducing the bond strength.

To attain the strong bond strength between the JH samples and the overlay, nano-silica treatment was also employed. Results of the single and combined (pour-applied) application of CNS indicates the improvement in the adhesion between the substrate and the repair material. In general, the largest bond strength was achieved by pour-applied nano-silica treated JH samples. The singular employment of CNS increased the adhesion by $53 \%$ when it is compared to the JH sample, and very importantly reaches the adhesion requirement for structural repair given by NBN EN 1504-3[48]. Szymanowski and Sadowski [16] added nano-silica in repair mortar and stated that a more compacted zone at the interphase between the substrate and the mortar was observed. However, they only observed a negligible improvement in the adhesion when a slight amount of nano-silica $(0.5 \%$ by weight of the cement) was used. Production of additional hydration products through the pozzolanic reaction between the CNS and the calcium hydroxide of the hardened cement paste was reported in [17]. According to these authors, CNS densifies the hardened cement paste by its filler effect and also by the pozzolanic reaction with the reaction products $\left(\mathrm{Ca}(\mathrm{OH})_{2}\right)$ of the hardened sample. The spray-applied combined treatment resulted in a lower bond strength than the pour-applied one, it could be because of an immediate reaction between silicate and calcium ions when they are mixed, forming a gel. This reaction might reduce the penetration of nano-silica and bacteria into the concrete and therefore lowers the effectiveness of the treatment in the bond strength development. Although it does not seem promising for the bond strength development, it can have other applications in repair systems, such as crack healing. The created gel can provide the optimal environment for the bacterial activation and assist the healing process.

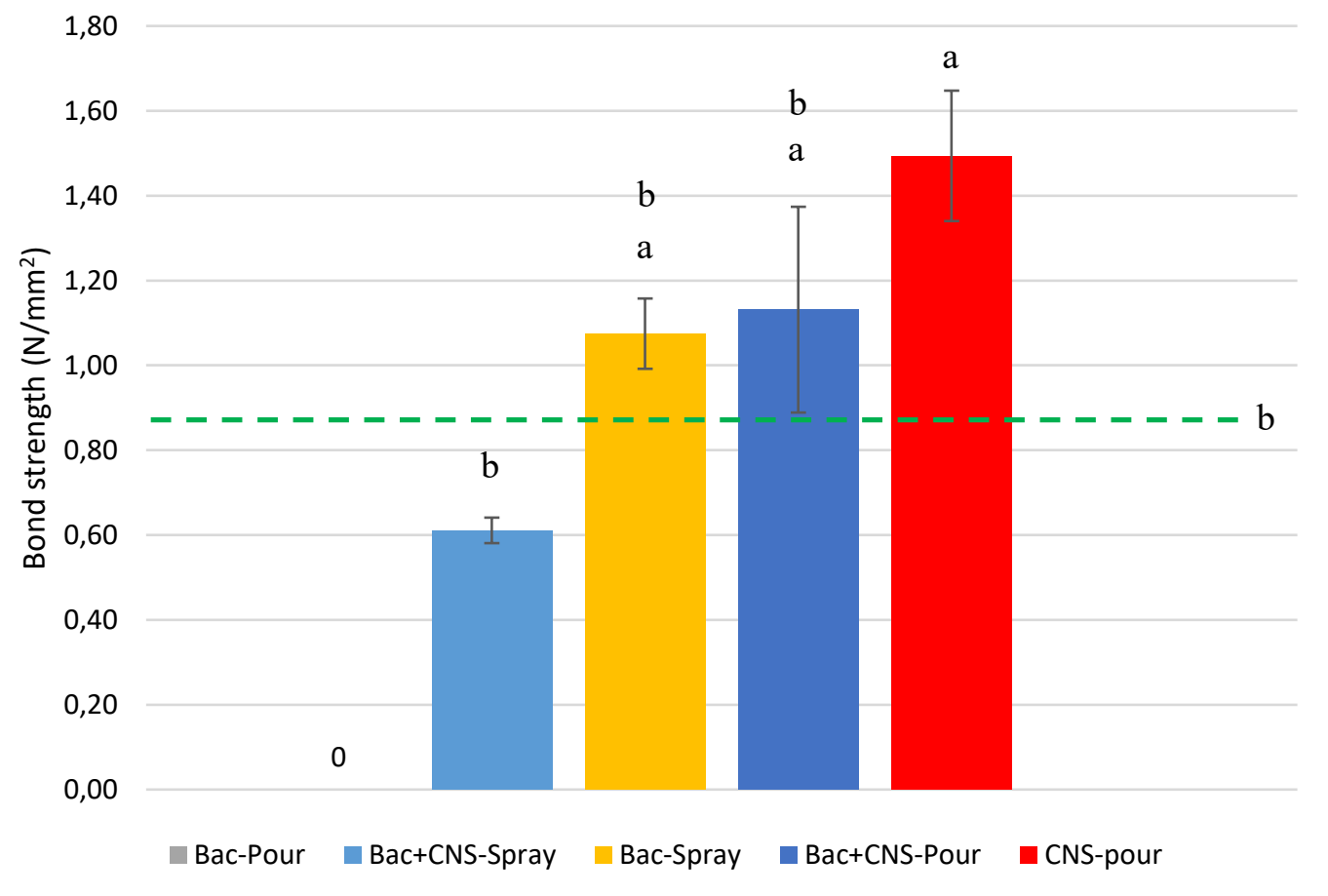

Figure 15. Bond strength results of JH-CC samples. Dashed line represents the control sample (JH-CC). Bac indicates bacterial treatment. Error bars represent the standard error. Means with the same letter indication are not significantly different. 


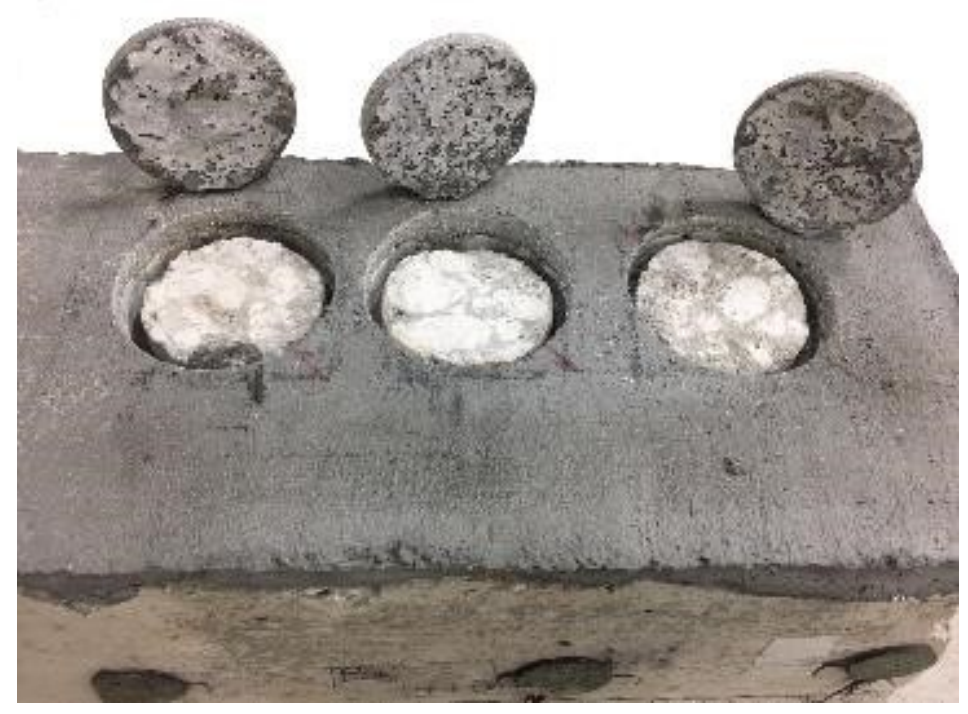

Figure 16. Pour-applied bacterial treatment - failure while drilling cores.

To make sure that the obtained results on the nano-silica treatments are reproducible another set of experiments were performed on GC slabs. Again the single and combined application of CNS was tried in this round as they had the largest impact on the bond strength between the $\mathrm{JH}-\mathrm{CC}$ concrete and the repair mortar. Bond strength results of GC substrates show the efficiency of CNS to improve the adhesion between the JH substrates and the overlay. Similar results as for CC substrates were achieved with GC substrates, gaining the largest adhesion by the single and followed by the combined application of the CNS and the biodeposition, see Figure 17. The singular application of CNS improved the BS of $\mathrm{JH}-\mathrm{GC}$ samples by $45 \%$. However, in this case, the differences between the means of CNS-treated GC and the untreated one were not statistically significant due to the high standard deviations, which is related to the low number of repetitions (three repetitions for each measurement). Interestingly, both the combined-pour-treated GC and CC achieved the same bond strength of $1.14 \pm 0.01 \mathrm{MPa}$.

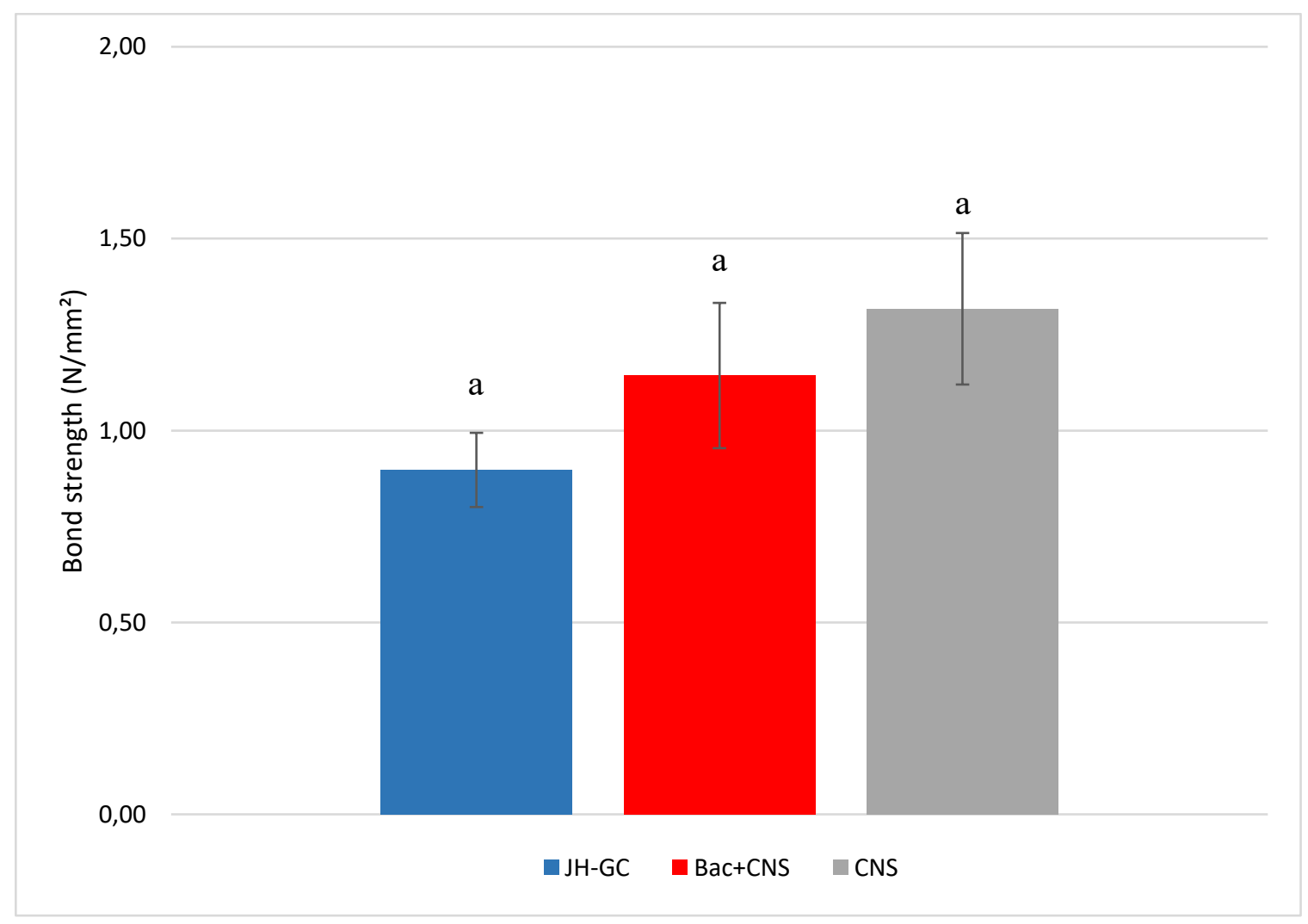


Figure 17. Bond strength results of JH-GC samples treated with the pouring technique. Error bars represent the standard error. Means with the same letter indication are not significantly different.

\subsection{Surface characterization - effect of colloidal nano-silica (CNS)}

Figure 18 shows the improvement of the STS of JH-CC and -GC samples after treatment with CNS. The increase in the STS is probably due to the chemical reaction between the NS and the $\mathrm{Ca}(\mathrm{OH})_{2}$ in the old concrete to form C-S-H. It can be inferred that the NS can react with the binder in the existing concrete and strengthen the deteriorated superficial layer of the substrate caused by the $\mathrm{JH}$. The reaction between the silicon dioxide and calcium hydroxide to form calcium-silicate-hydrate has been reported widely $[17,19,20,49]$. Kupwade-Patil et al. [49] reported a reduction in $\mathrm{Ca}(\mathrm{OH})_{2}$ by $8 \%$ resulting from nanoparticle (alumina-coated silica) treatment of hardened concrete samples. They transported nanoparticles to the surface of reinforcement through capillary pores for the mitigation of corrosion. One additional finding of their study was the higher production rate of C-S-H gel by the reaction of the $\mathrm{Ca}(\mathrm{OH})_{2}$ within the hardened concrete and the silica component of the transported nanoparticles. Sanchez et al. [19] also confirmed the possibility of the reaction between CNS and the cement paste when hardened samples were treated with CNS. Hou et al. [20] compared nano-silica with silica fume in consumption of $\mathrm{Ca}(\mathrm{OH})_{2}$ and reported that the former only needs 7 days compared to the 28 days for silica fume to complete the reaction, expressing the fast reaction of NS. In this study, the STS experiments were performed 6-7 days after the application of CNS. The authors aim to further study the reaction between the silica gel and hardened paste and also the STS of CNS-treated substrates in the near future.

Moreover, in Figure 19 it is observed that the water uptake of samples treated with CNS is initially (up to $120 \mathrm{~min}$ ) slightly lower than that of the unaltered JH sample. The later increase in the water uptake of CNS-treated samples might be because of the reduction in the density of the silica gel at the surface of the concrete throughout the experiment. However, the initial reduction in the water uptake might be due to the pore-blocking effect of the precipitated amorphous NS. It implies the existence and activity of NS at the superficial layer of the substrate. In this case, NS in turn has the potential to contribute to the further nucleation of reaction products of the repair mortar when the overlay is applied, boosting the interlocking between the two composites. Application of the overlay will enhance the moisture content at the interface and therefore provide an optimal environment for the activity of the remaining NS at the subsurface of the concrete substrate. One could take this observation to explain why JH samples treated with CNS achieved the largest bond strength with the overlay. CNS was claimed to precipitate and condense at the surface of hardened cement pastes, leading to the domination of amorphous $\mathrm{SiO}_{2}$ at the surface [17] and acting as nucleation sites on anhydrous cement particles [19]. Hou et al., explained that an additional C-S-H gel with a higher stiffness compared to that of the plain paste is formed on the surface of hardened samples treated with CNS $[17,20]$. In [21] the initial water absorption of cement paste after surface treatment by CNS was studied. They showed that the effect of surface treatment on the water uptake of samples is dependent on the porosity of the mixture; for samples with w/c ratios of 0.6 and 1, a great reduction in the water uptake was observed. The pore-refining of hardened samples treated with CNS was also observed $[17,21]$. As the surface treatment in this study was performed on JH samples, CNS may have a higher chance of penetration into the substrate because of the microcracks caused by the JH. Nevertheless, the water uptake results of this study show the negligible impact of removal techniques. The influence of silicates acting as pore-blockers has been reported in $[12,13,15]$. Some claim that the efficacy of the silicates in improving the performance of concrete is by the consumption of free $\mathrm{Ca}$ or calcium hydroxide at the surface of the concrete and production of $\mathrm{C}-\mathrm{S}-\mathrm{H}$ $[15,17,21,50]$. In both the soluble silicate-based impregnation treatments (e.g. water glass) and the proposed treatment in this study the pore-blocking takes place by the reaction products of silica and paste and/or the precipitation of $\mathrm{SiO}_{2}$ in the pores (in the hardened sample) [15] not by a physical coating-barrier. 


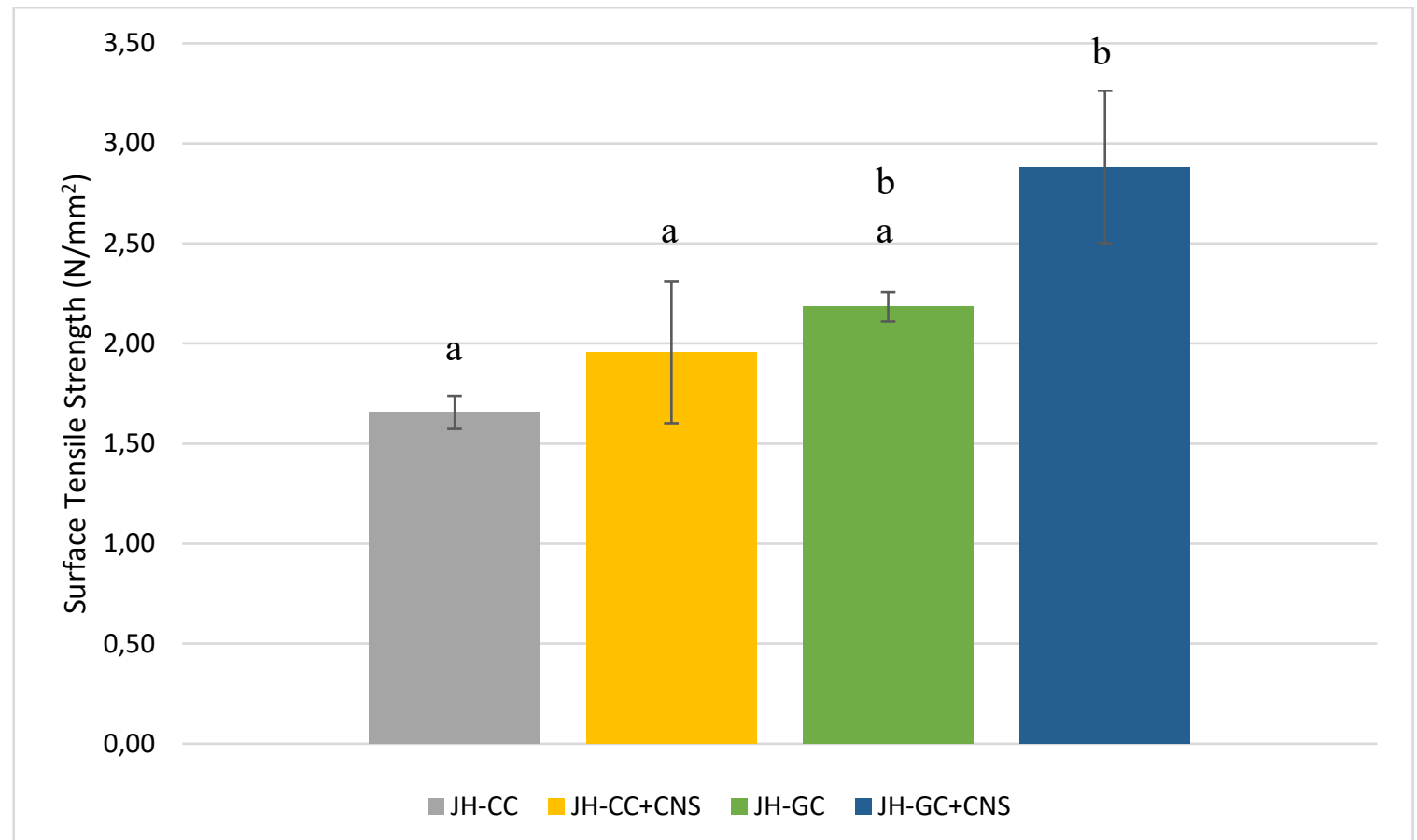

Figure 18. Surface tensile strength results of JH-CC and -GC samples with and without CNS treatment. Error bars represent the standard error. Means with the same letter indication are not significantly different.

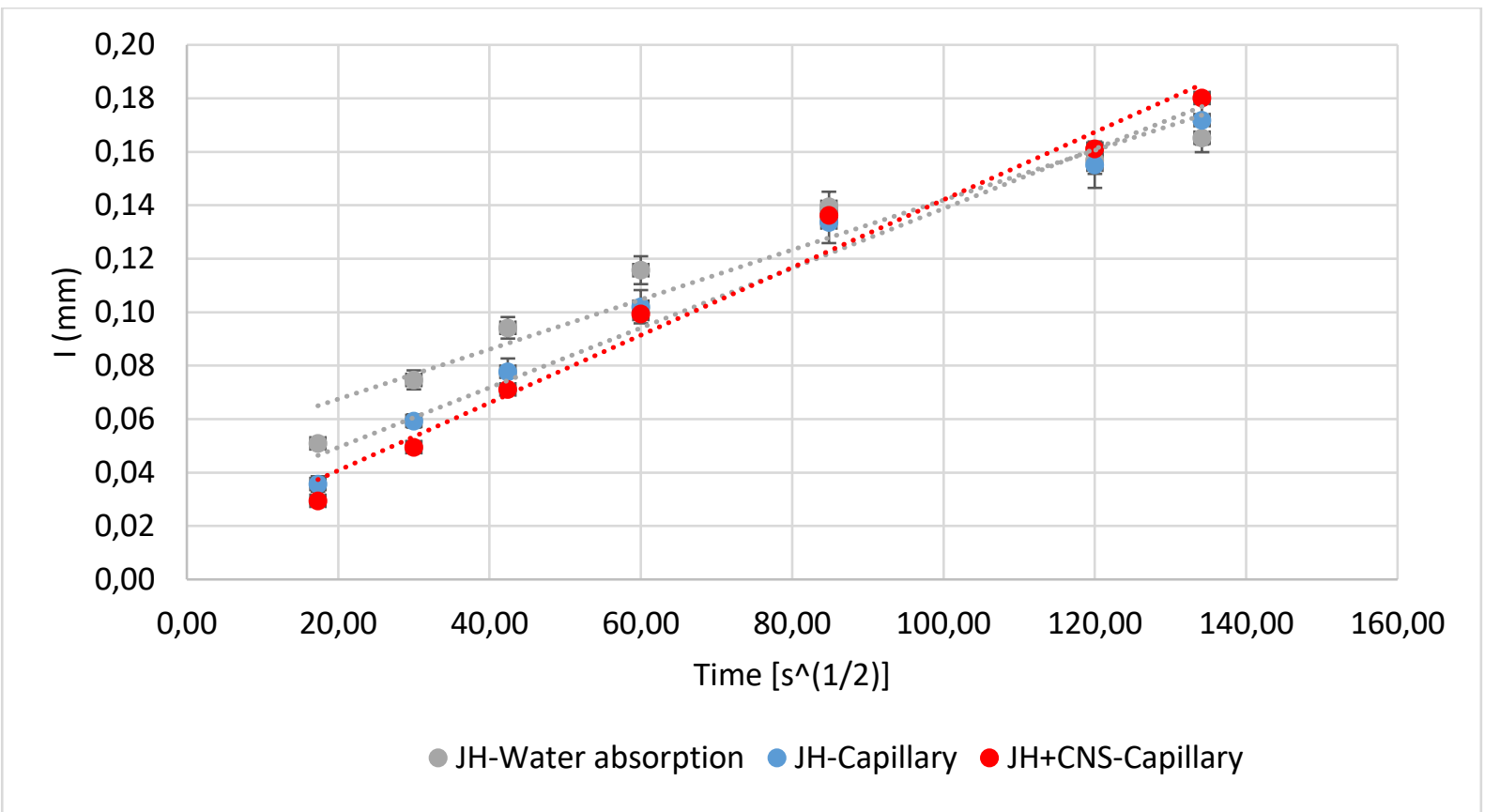

Figure 19. Water uptake of JH-CC and CNS-treated JH-CC samples. Error bars represent the standard error.

\subsection{Microscopy image analysis}

The microstructure of the interphase in layered composites is very important to study as it is in turn related to the adhesion between the two layers [51]. Nevertheless, the interlayer zone must be first distinguished. In this study, the determination of the interlayer was done with the assistance of EDX analysis. In addition, the micromechanical properties between the cement matrix of the overlay and the aggregates of the substrate are of high importance as $60-70 \%$ of the substrate surface is occupied with aggregates (see Figure 20 (c) \& (f)). Such composition is clearly shown in the EDX image given in Figure $20 \mathrm{~b}-\mathrm{c}$ and e-f, showing the effectiveness of the EDX analysis to find spots at which there is a connection between aggregates and cement matrix. In general, the hard task to study the micromechanical behaviour at the interface is first to distinguish this layer, namely for composites with 
a large bonding which are almost monolithic such as CNS-treated samples in this study, see Figure 20 (a) \& (d). The transition zone that is formed when the existing concrete is covered with repair material is very similar to the interfacial transition zone between aggregates and cement paste in concrete $[4,52]$, being very porous. Figure 21 shows a clear example of interaction between the aggregates of the substrate and the paste of the overlay. This supports the theory that an ITZ exists between an old and new concrete, representing a zone of weakness. In terms of the CNS treatment, it is expected that the remaining CNS on the substrate will boost the hydration and therefore strengthen the interfacial zone in between the two composites. Jamsheer et al. [18] revealed that the reaction of NS and cement paste produces additional Si polymerization in C-S-H gel and also facilitates its nucleation. In a study performed by Ping et al. [53] aggregate surfaces were coated with a layer of silica fume to enhance the microstructure in the transition zone. Researchers in [45] improved the ITZ between the concrete substrate and the overlay using a fly ash-modified primer. Silicon dioxide coating of carbon fibers was reported to improve the bond strength between the fibers and the concrete matrix by the local formation of C-S-H gel [54].

On the other hand, the interfacial zone between the substrate and the overlay can be divided into three different layers based on the structure of pores [37]. The near surface zone of the concrete substrate $(<3 \mathrm{~mm})$, the meso-interphase zone of concrete layers (1-2 $\mathrm{mm}$ depending on the removal technique) and the near surface zone of the overlay mortar $(<3 \mathrm{~mm})$. However, this classification is expected to be highly dependent on the applied removal technique. The meso-interphase zones are somehow evident and shown in SEM-EDX images of this study, see Figure $20 \mathrm{~b}-\mathrm{c}$ and e-f. According to the results given in [37], an increase in the number and the values of the fraction of pores in the near surface zone of the overlay and the meso-interphase leads to a reduction in the pull-off adhesion between the substrate and the repair material. As shown in Figure 22, some pores are observed in the meso-interphase zone of JH$\mathrm{CC}$ samples. Concerning the bond strength, these samples (JH-CC) achieved the lowest bond strength compared to other samples. However, a dense interlayer is observed for JH-CC treated with CNS. An important role of CNS in the microstructure formation of the bonding zone is evident according to the SEM-EDX analysis (see Figures 20 and 21). Amorphous silica at the interface zone seems to have enhanced the nucleation with the repair mortar and formed a dense microstructure at the interlayer between the substrate and the repair material. 

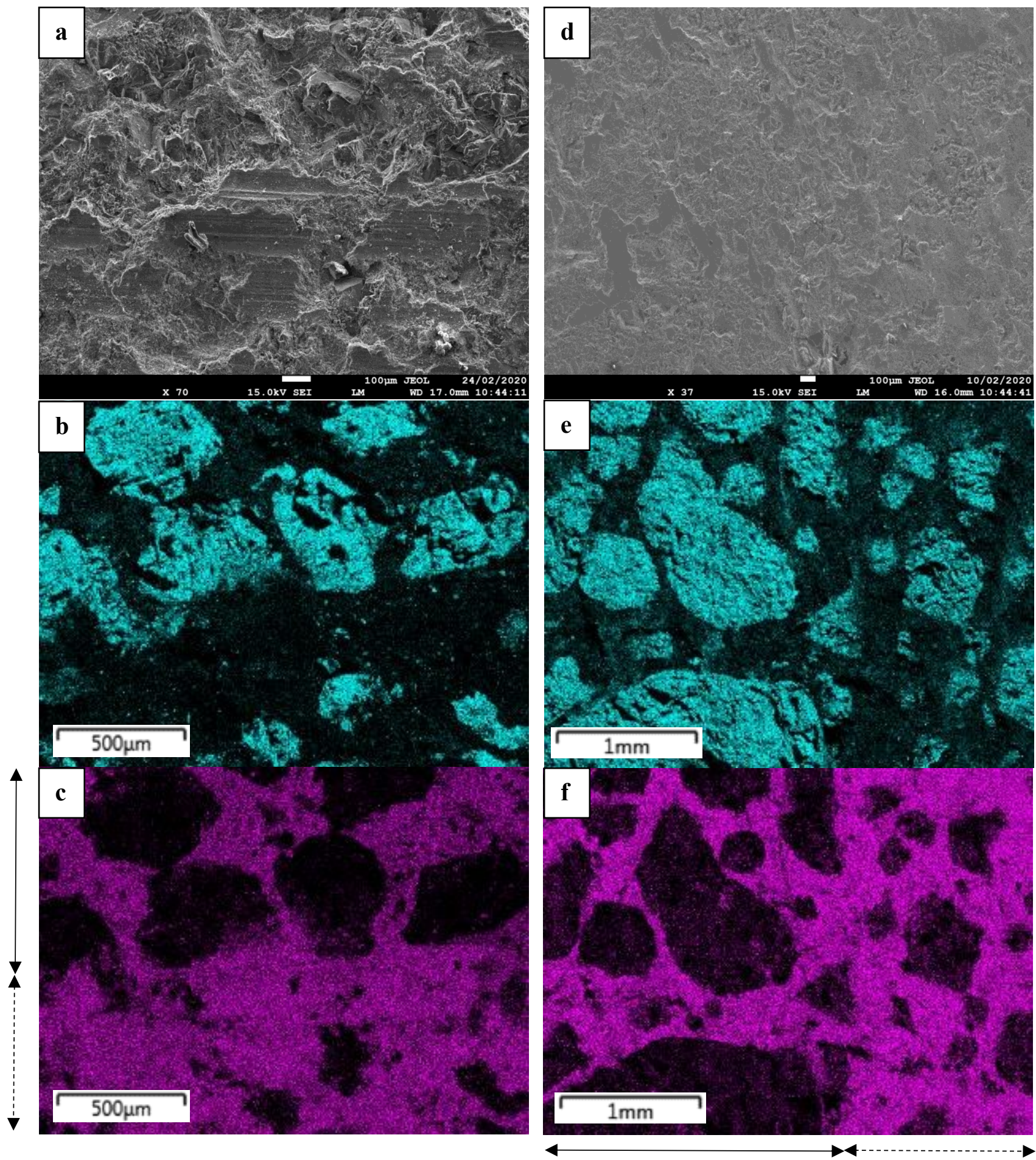

Figure 20. SEM-EDX images of CNS-treated JH-CC samples. Images a-c belong to sample 1 and d-f to sample 2. Scale bars equal $100 \mu \mathrm{m}$ for the SEM images a and $\mathrm{d}, 500 \mu \mathrm{m}$ for images $\mathrm{b}$ and $\mathrm{c}$ and $1 \mathrm{~mm}$ for images e and f. Images $b$ and e as well as $c$ and $f$ show the silicon and calcium in green and red, respectively. Dashed arrows show the overlay and solid arrows show the concrete substrate. 

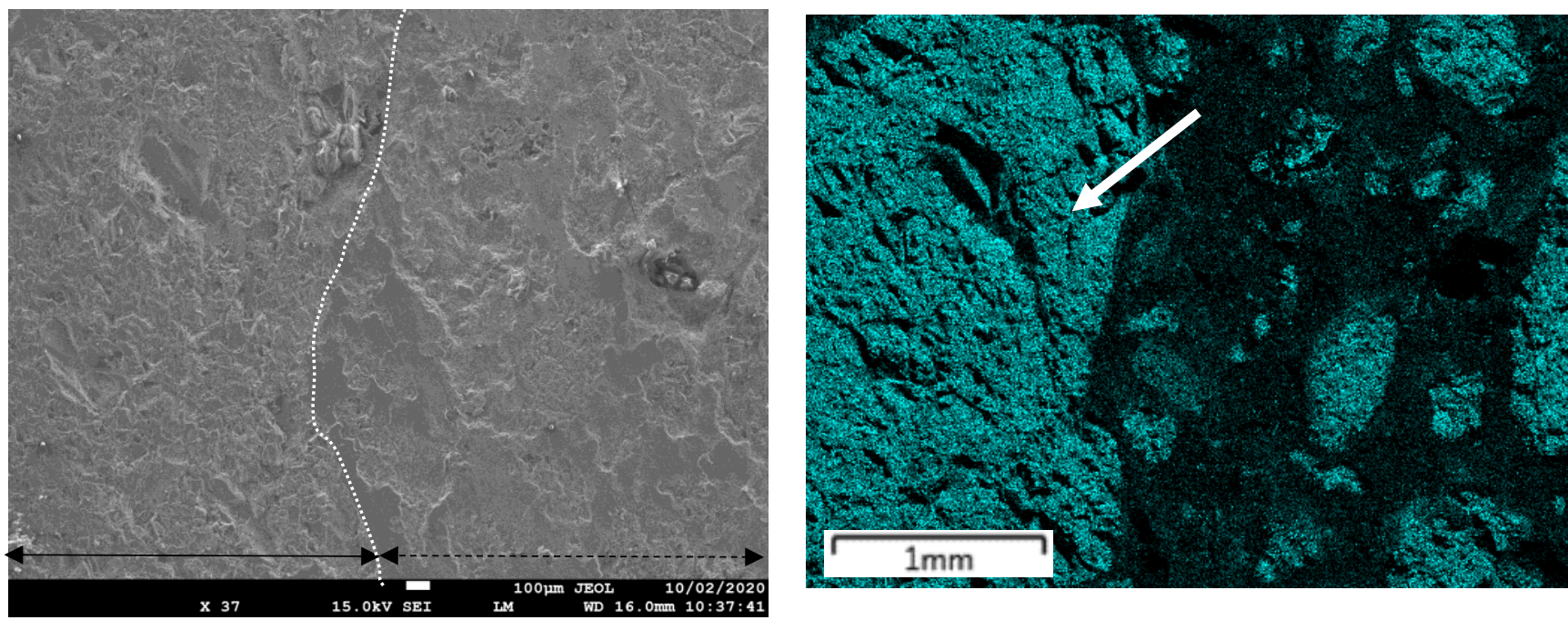

Figure 21. SEM (left) and EDX (right) images of CNS-treated JH sample 2. Scale bars equal $100 \mu \mathrm{m}$ for the SEM image (left) and $1 \mathrm{~mm}$ for the EDX image (right). Green in the image (right) shows the silicon; an example of a siliceous grain is also shown by the arrow. In the SEM image (left), dashed arrow shows the overlay and solid arrow shows an aggregate in the concrete substrate. The Dashed line in the middle of the SEM image (left) indicates an approximation of the boundary between the layers.
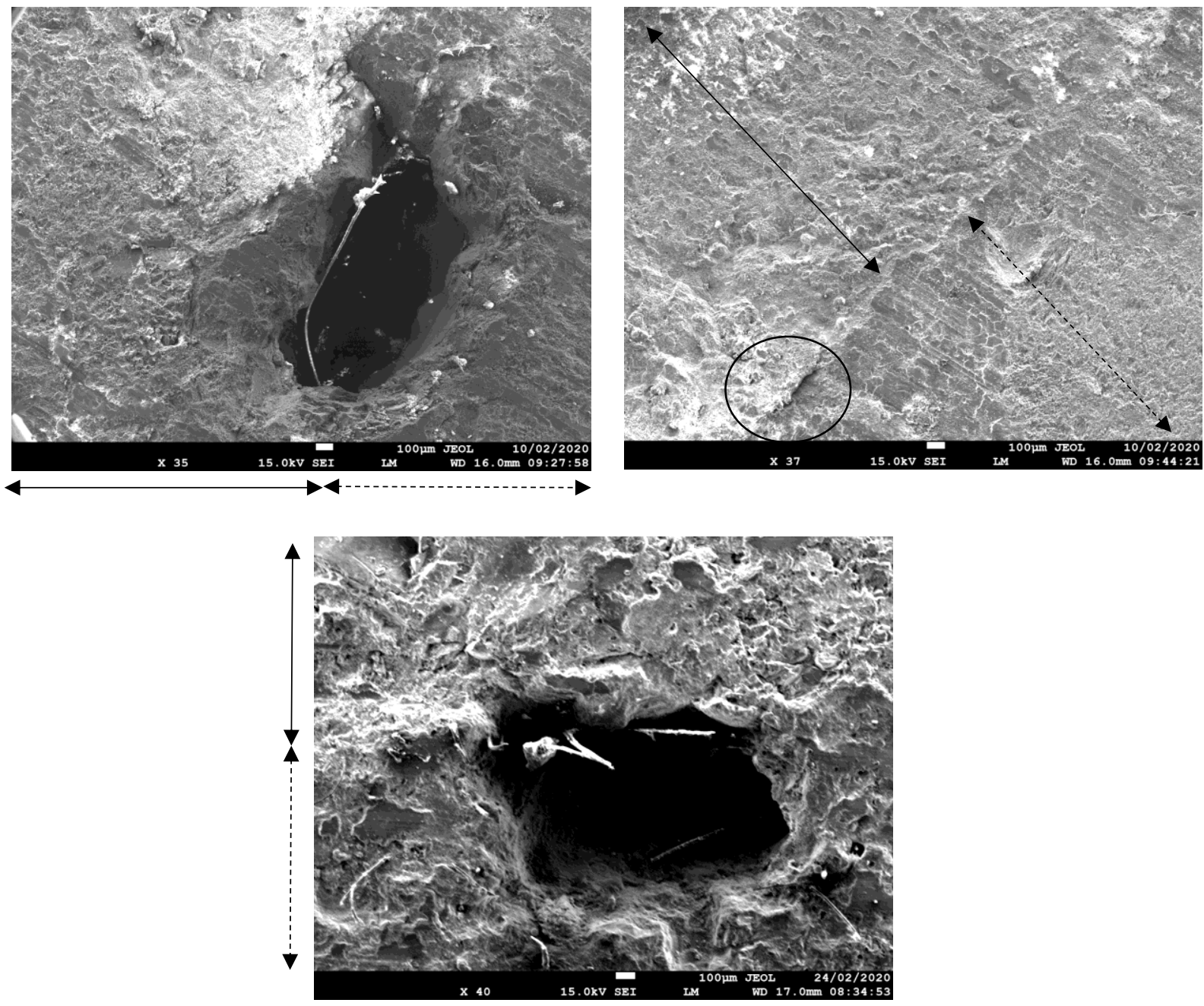

Figure 22. SEM images of JH samples. Sample 2 (top) and sample 1 (bottom). Scale bars equal $100 \mu \mathrm{m}$. Dashed arrows show the overlay and solid arrows show the concrete substrate. The encircled zone shows debonding. 


\section{Conclusions}

In this study, different removal techniques (water jetting (WJ) and jackhammering (JH)) were compared and the one $(\mathrm{JH})$ with the largest detrimental effects on the bond strength between the concrete substrate and the overlay was chosen for further investigations. Thereafter, JH substrates were exposed to surface treatment with colloidal nano-silica (CNS), biodeposition and their combined application. The main outcomes of the study are reported as follows:

- WJ substrates achieved a larger surface roughness compared to JH substrates. However, JH substrates compared to WJ and unprepared substrates achieved the lowest bond strength (BS) and surface tensile strength (STS), showing the unimportant influence of the roughness on the tensile bond strength. Nevertheless, a slight increase only in the bond strength of waterjetted crushed limestone concrete (WJ-CC)was observed when the results were compared at different ages of 28 days and 12 months, probably indicating the influence of parameters such as roughness on the durability of the bonding.

- Water uptake results showed the moderate impact of removal techniques on the substrate absorption. However, the vacuum absorption test results indicated a significant difference between the open porosity of unprepared samples compared to JH samples.

- When surface treatment methods were compared, the spray-applied biodeposition treatment seemed to be superior to the pour-applied one. Author's suggestion is to avoid creation of any extra interface in between the old and new layer. The singular application of CNS resulted in the highest adhesion between the $\mathrm{JH}$ substrate and the overlay, proposing a promising solution to restore the lost bond strength induced by JH. Application of CNS improved the adhesion by $53 \%$ compared to the control sample $(\mathrm{JH})$.

- STS of JH samples treated with CNS was evident of the influence of CNS in strengthening the superficial layer of the substrate. Moreover, the water absorption results showed an initial reduction in the water uptake of CNS-treated JH substrates, evidencing the precipitation of the silica gel at the subsurface of substrate.

- EDX showed to be assisting in the recognition of the interlayer specifically for monolithic composites, revealing a promising method to ease the investigation of the microstructure of the interlayer in layered composites. Some pores were observed in the SEM images of JH samples. However, a dense microstructure was observed at the interphase zone of the CNS-treated substrates.

In the current study, application of CNS is suggested to restore the lost tensile bond strength between the JH substrate and the overlay. To facilitate the practical application of CNS in the repair systems the authors aim to investigate the spray application of CNS and also the durability of CNS-treated JH substrate.

\section{Acknowledgements}

The authors would like to acknowledge the BOF Grant BOF.24Y.2017.0025.01 from Ghent University for the research project "Innovative, multifunctional repair technique to extend the service life of concrete structures". Special thanks are also given to the Crahay company for water jetting demolition of substrates and GRACE company, the supplier of the colloidal nano-silica (CNS).

\section{References:}

[1] M.A. Yazdi, E. Dejager, M. Debraekeleer, E. Gruyaert, K. Van Tittelboom, N. De Belie, Bond strength between concrete and repair mortar and its relation with concrete removal techniques and substrate composition, Construction and Building Materials 230 (2020) 116900.

[2] M.A. Yazdi, E. Dejager, M. Debraekeleer, E. Gruyaert, K. Van Tittelboom, N. De Belie, How concrete removal techniques affect the bonding between concrete and repair mortar, MATEC Web of Conferences, EDP Sciences, Cluj, Romania (2019). 
[3] L. Courard, T. Piotrowski, A. Garbacz, Near-to-surface properties affecting bond strength in concrete repair, Cement and Concrete Composites 46 (2014) 73-80.

[4] B. Bissonnette, L. Courard, D.W. Fowler, J.L. Granju, Bonded Cement-based Material Overlays for the Repair, the Lining or the Strengthening of Slabs or Pavements: State-of-the-art Report of the RILEM Technical Committee 193-RLS, Springer Science \& Business Media, (2011).

[5] C. Talbot, M. Pigeon, D. Beaupré, D. Morgan, Influence of surface preparation on long-term bonding of shotcrete, ACI Materials Journal 91(6) (1995) 560-566.

[6] L. Courard, B. Bissonnette, N. Belair, Effect of surface preparation techniques on the cohesion of superficial concrete: comparison of jack-hammering and water jetting, Concrete Repair, Rehabilitation and Retrofitting, Taylor \& Francis Group, Cape Town, South Africa, (2006), p. 383.

[7] P. Carter, S. Gurjar, J. Wong, Debonding of highway bridge deck overlays, Concrete International 24(7) (2002) 51-58.

[8] M.A. Champ, Economic and environmental impacts on ports and harbors from the convention to ban harmful marine anti-fouling systems, Marine Pollution Bulletin 46(8) (2003) 935-940.

[9] M.C. Vorster, J.P. Merrigan, R.W. Lewis, R.E. Weyers, Techniques for concrete removal and bar cleaning on bridge rehabilitation projects, (1992).

[10] M. Sánchez, P. Faria, L. Ferrara, E. Horszczaruk, H. Jonkers, A. Kwiecień, J. Mosa, A. Peled, A. Pereira, D. Snoeck, External treatments for the preventive repair of existing constructions: A review, Construction and Building Materials 193 (2018) 435-452.

[11] L. Baltazar, J. Santana, B. Lopes, M.P. Rodrigues, J.R. Correia, Surface skin protection of concrete with silicate-based impregnations: Influence of the substrate roughness and moisture, Construction and Building Materials 70 (2014) 191-200.

[12] E. Franzoni, B. Pigino, C. Pistolesi, Ethyl silicate for surface protection of concrete: performance in comparison with other inorganic surface treatments, Cement and Concrete Composites 44 (2013) 6976.

[13] F. Sandrolini, E. Franzoni, B. Pigino, Ethyl silicate for surface treatment of concrete-Part I: Pozzolanic effect of ethyl silicate, Cement and Concrete Composites 34(3) (2012) 306-312.

[14] G. Fajardo, A. Cruz-López, D. Cruz-Moreno, P. Valdez, G. Torres, R. Zanella, Innovative application of silicon nanoparticles (SN): Improvement of the barrier effect in hardened Portland cement-based materials, Construction and Building Materials 76 (2015) 158-167.

[15] J.L. Thompson, M. Silsbee, P. Gill, B. Scheetz, Characterization of silicate sealers on concrete, Cement and Concrete Research 27(10) (1997) 1561-1567.

[16] J. Szymanowski, Ł. Sadowski, Functional and adhesive properties of cement-based overlays modified with amorphous silica nanospheres, The Journal of Adhesion 96(1-4) (2020) 207-228.

[17] P. Hou, X. Cheng, J. Qian, S.P. Shah, Effects and mechanisms of surface treatment of hardened cement-based materials with colloidal nanoSiO${ }_{2}$ and its precursor, Construction and Building Materials 53 (2014) 66-73.

[18] A.F. Jamsheer, K. Kupwade-Patil, O. Büyüköztürk, A.J.C. Bumajdad, Analysis of engineered cement paste using silica nanoparticles and metakaolin using ${ }^{29} \mathrm{Si} \mathrm{NMR}$, water adsorption and synchrotron X-ray Diffraction, Construction and Building Materials 180 (2018) 698-709.

[19] M. Sanchez, M. Alonso, R. González, Preliminary attempt of hardened mortar sealing by colloidal nanosilica migration, Construction and Building Materials 66 (2014) 306-312.

[20] P. Hou, S. Kawashima, D. Kong, D.J. Corr, J. Qian, S.P. Shah, Modification effects of colloidal nanoSiO 2 on cement hydration and its gel property, Composites Part B: Engineering 45(1) (2013) 440448.

[21] P. Hou, X. Cheng, J. Qian, R. Zhang, W. Cao, S.P. Shah, Characteristics of surface-treatment of nano- $\mathrm{SiO}_{2}$ on the transport properties of hardened cement pastes with different water-to-cement ratios, Cement and Concrete Composites 55 (2015) 26-33.

[22] K.L. Bachmeier, A.E. Williams, J.R. Warmington, S.S. Bang, Urease activity in microbiologicallyinduced calcite precipitation, Journal of Biotechnology 93(2) (2002) 171-181.

[23] S.S. Bang, J.K. Galinat, V. Ramakrishnan, Calcite precipitation induced by polyurethaneimmobilized Bacillus pasteurii, Enzyme Microbial Technology 28(4-5) (2001) 404-409.

[24] S.K. Ramachandran, V. Ramakrishnan, S.S. Bang, Remediation of concrete using microorganisms, ACI Materials Journal 98(1) (2001) 3-9. 
[25] W. De Muynck, D. Debrouwer, N. De Belie, W. Verstraete, Bacterial carbonate precipitation improves the durability of cementitious materials, Cement and Concrete Research 38(7) (2008) 1005 1014.

[26] W. De Muynck, K. Cox, N. De Belie, W. Verstraete, Bacterial carbonate precipitation as an alternative surface treatment for concrete, Construction and Building Materials 22(5) (2008) 875-885.

[27] J. Dick, W. De Windt, B. De Graef, H. Saveyn, P. Van der Meeren, N. De Belie, W. Verstraete, Bio-deposition of a calcium carbonate layer on degraded limestone by Bacillus species, Biodegradation 17(4) (2006) 357-367.

[28] P. Tiano, L. Biagiotti, G. Mastromei, Bacterial bio-mediated calcite precipitation for monumental stones conservation: methods of evaluation, Journal of Microbiological Methods

36(1-2) (1999) 139-145.

[29] N. Chahal, R. Siddique, A.J.C. Rajor, B. Materials, Influence of bacteria on the compressive strength, water absorption and rapid chloride permeability of fly ash concrete, 28(1) (2012) 351-356.

[30] D. Snoeck, J. Wang, D.P. Bentz, N. De Belie, Applying a biodeposition layer to increase the bond of a repair mortar on a mortar substrate, Cement and Concrete Composites 86 (2018) 30-39.

[31] W. De Muynck, N. Boon, N. De Belie, From lab scale to in situ applications: the ascent of a biogenic carbonate based surface treatment, XIII International Conference on Durability of Building Materials and Components (XIII DBMC), (2014), p. 728-735.

[32] N. De Belie, J. Monteny, A. Beeldens, E. Vincke, D. Van Gemert, W. Verstraete, Experimental research and prediction of the effect of chemical and biogenic sulfuric acid on different types of commercially produced concrete sewer pipes, Cement and Concrete Research 34(12) (2004) 2223-2236. [33] BSI, Assessment of surface texture - Guidance and general information, BS 1134, BSI Standards Publication, (2010).

[34] ASTM, Standard test method for measurement of rate of absorption of water by hydraulic cement concretes, ASTM C 1585, (2011).

[35] DIN, Products and systems for the protection and repair of concrete structures-Test methodsMeasurement of bond strength by pull-off, EN 1542, The Bureau for Standardisation (NBN), (1999).

[36] F. Perez, M. Morency, B. Bissonnette, L. Courard, Correlation between the roughness of the substrate surface and the debonding risk, 2nd International Conference on Concrete Repair, Rehabilitation and Retrofitting, ICCRRR-2 CRC Press, Cape Town, South Africa, (2008), p. 24-26

[37] $Ł$. Sadowski, D. Stefaniuk, J. Hoła, The effect of the porosity within the interfacial zone between layers on pull-off adhesion, Construction and Building Materials 152 (2017) 887-897.

[38] L. Courard, J.-F. Lenaers, F. Michel, A. Garbacz, Saturation level of the superficial zone of concrete and adhesion of repair systems, Construction and Building Materials 25(5) (2011) 2488-2494.

[39] L. Courard, R. Degeimbre, A capillary action test for the investigation of adhesion in repair technology, Canadian Journal of Civil Engineering 30(6) (2003) 1101-1110.

[40] J. Silfwerbrand, Improving concrete bond in repaired bridge decks, Concrete International 12(9) (1990).

[41] B. Bissonnette, A.M. Vaysburd, K.F. von Fay, Best practices for preparing concrete surfaces prior to repairs and overlays, (2012).

[42] H.-D. Beushausen, Long-term performance of bonded concrete overlays subjected to differential shrinkage, University of Cape Town, (2005).

[43] L. Costa, G. Olyveira, R. Salomão, Precipitated calcium carbonate nano-microparticles: Applications in drug delivery, Adv Tissue Eng Regen Med Open Access 3(2) (2017) 00059.

[44] V. Wiktor, H. Jonkers, Assessment of the functionality of bacteria-based repair system for concrete through ESEM analysis, EMABM: Proceedings of the 15th Euroseminar on Microscopy Applied to Building Materials, Delft, The Netherlands, (2015).

[45] G. Xiong, J. Liu, G. Li, H. Xie, A way for improving interfacial transition zone between concrete substrate and repair materials, Cement and Concrete Research 32(12) (2002) 1877-1881.

[46] E.K. Schrader, Mistakes, Misconceptions, and Controversial Issues Concerning Concrete and Concrete Repairs, Part 3, Concrete International 14(11) (1992) 54-59.

[47] J.T. Champa, R. Gulyas, G. Wirthlin, Evaluation of keyway grout test methods for precast concrete bridges, PCI Journal (1995) 44-57. 
[48] DIN, Products and systems for the protection and repair of concrete structures - Definitions, requirements, quality control and evaluation of conformity - Part 3: Structural and non-structural repair, EN 1504-3, The Bureau for Standardisation (NBN), (2006).

[49] K. Kupwade-Patil, H.E. Cardenas, K. Gordon, L.S. Lee, Corrosion Mitigation in Reinforced Concrete Beams via Nanoparticle Treatment, ACI Materials Journal 109(6) (2012).

[50] A.M. Said, M.S. Zeidan, M. Bassuoni, Y. Tian, Properties of concrete incorporating nano-silica, Construction and Building Materials 36 (2012) 838-844.

[51] Ł. Sadowski, D. Stefaniuk, A. Żak, K. Krakowiak, Micromechanical properties within the interphase between heterogeneous layers made of cementitious composites, Construction and Building Materials 215 (2019) 1033-1043.

[52] A. Carles-Gibergues, F. Saucier, J. Grandet, M. Pigeon, New-to-old concrete bonding: influence of sulfates type of new concrete on interface microstructure, Cement and Concrete Research 23(2) (1993) 431-441.

[53] X. Ping, J.J. Beaudoin, Modification of transition zone microstructure-silica fume coating of aggregate surfaces, Cement and Concrete Research 22(4) (1992) 597-604.

[54] J. Zhao, M. Liebscher, A. Michel, K. Schneider, Rü. Foest, M. Fröhlich, A. Quade, V. Mechtcherine, Plasma-generated silicon oxide coatings of carbon fibres for improved bonding to mineral-based impregnation materials and concrete matrices, Cement and Concrete Composites (2020). 